\title{
Two-dimensional structure of mountain wave observed by aircraft during the PYREX experiment
}

\author{
J. L. Attié, A. Druilhet, P. Durand, B. Bénech \\ Laboratoire d'Aérologie CNRS-UMR 5560, Université Paul Sabatier, O.M.P, 14 Av. Edouard Belin 31400 Toulouse, France
}

Received: 17 July 1996 / Revised: 2 December 1996 / Accepted: 10 December 1996

\begin{abstract}
This study presents an experimental analysis from aircraft measurements above the Pyrenees chain during the PYREX experiment. The Pyrenees chain, roughly WE oriented, is a major barrier for northerly and southerly airflows. We present a case of southerly flow (15 October 1990) and three successive cases of northerly flows above the Pyrenees (14, 15 and 16 November 1990) documented by two aircraft. The aircraft have described a vertical cross section perpendicular to the Pyrenean ridge. This area is described via the thermodynamical and dynamical fields which have a horizontal resolution of $10 \mathrm{~km}$. Three methods for computing the vertical velocity of the air are presented. The horizontal advection terms which play a role in the budget equations are also evaluated. The altitude turbulence zone of 15 October are shown via turbulent fluxes, turbulent kinetic energy (TKE), dissipation rate of TKE and inertial length-scale. A comparison of results obtained by eddy-correlation and inertial-dissipation method is presented. The experimental results show a warm and dry downdraft for the southerly flow with large values for advection terms. All the mountain wave cases are also shown to present an important dynamical perturbation just above the Pyrenees at upper altitudes.
\end{abstract}

\section{Introduction}

The interaction between the atmospheric airflow and a mountain was first a problem of roughness on the atmospheric circulation (Lilly, 1972). The 1970 Colorado Lee Wave Program targeted the Rocky Mountains (Lilly and Kennedy, 1973), and the ALPEX program spread observational nets around and over the

Correspondence to: J. L. Attié
Alps (Küettner, 1986). However, experimental studies aimed at evaluating the global effect of a mountain chain are limited, due to the difficulty of taking into account every scale in the airflow. However, some mechanisms have been studied, in particular the transport of momentum in lee waves: see for instance: Lilly et al. (1982) (Rocky Mountains), Brown (1983) (British Isles), Hoinka (1984, 1985) (Pyrenees and Alps) and Kim and Mahrt (1992). In addition, many theoretical and modelling works have been performed (see the review by Smith, 1979, Durran and Klemp, 1982, 1983; Durran, 1986; Xue and Thorpe, 1991). Recent numerical models have been successfully used to describe the mesoscale effects induced by a mountain chain. In particular, the non-hydrostatic model of Clark (1977) used by Hoinka and Clark (1991) or Clark and Miller (1991) satisfactorily described the fundamental dynamics of mountain waves above the Alps.

Knowledge of the perturbation associated with relief requires a gathering of reference data set at different scales, first to improve the parametrizations in models and secondly to study the orographic mechanisms such as mountain wave or rotors on the lee side of the mountain. These goals were the motivation for the PYREX experimental program (Bougeault et al., 1990, 1993). The PYREX experiment took place in the region of the Pyrenees during 10 intensive observation periods (IOP) in October and November 1990. Bougeault (1994) set the problem of the validation of a $2 \mathrm{D}$ approach of orographic airflows, whereas Elkhalfi et al. (1995) have shown 2D numerical simulations of PYREX mountain wave cases. We present the aircraft data assuming the 2D approach and we consider the stationarity of the airflow during the flight period varying (between 3 and $6 \mathrm{~h}$ ). The aircraft data describe the airflow in a central vertical crosssection, perpendicular to the Pyrenees chain. In this work, we study four cases of mountain wave during PYREX: a southerly airflow (15 October 1990: IOP-3) and three successive cases of northerly airflows above the Pyrenees (14, 15 and 16 November 1990, IOP-9). These various days are considered as the 
best mountain wave cases investigated by aircraft during PYREX. We present a summary of the experimental set and the instrumentation of the research aircraft whose data are used here (Sect. 2 and 3). The wave cases are characterized by the meteorological situation (Sect. 4) and the driving parameters such as the Brunt Väisälä frequency and the Froude number calculated from data of upstream radiosonde soundings (Sect. 5). In Sect. 6, the 15 October case is studied with $2 \mathrm{D}$ fields that allow first to present (for a scale greater than $10 \mathrm{~km}$ ) firstorder variables such as wind, potential temperature and specific humidity, and secondly more elaborate variables such as horizontal advection terms. The turbulent fluxes (sensible heat flux and momentum) are computed above the mountain on 15 October, by eddy-correlation and inertial-dissipation methods. Thirdly, we present in Sect. 7 the analysis of aircraft data for the three successive northerly flow cases above the Pyrenees.

\section{Experimental set}

The Pyrenees chain, nearly $400 \mathrm{~km}$ in length and roughly WE oriented, is a major barrier for northerly and southerly airflows. The chain stretches from the Atlantic Ocean to the Mediterranean Sea with a width varying from 50 to $80 \mathrm{~km}$ and an average height of $2300 \mathrm{~m}$. The highest point at $3404 \mathrm{~m}$ is the Aneto peak located in the central area. A summary of the experimental data sources is presented in Fig. 1. An important network of radiosonde soundings around the mountain chain allowed evaluation of the airflow modification due to the relief, and specification of the input and validation

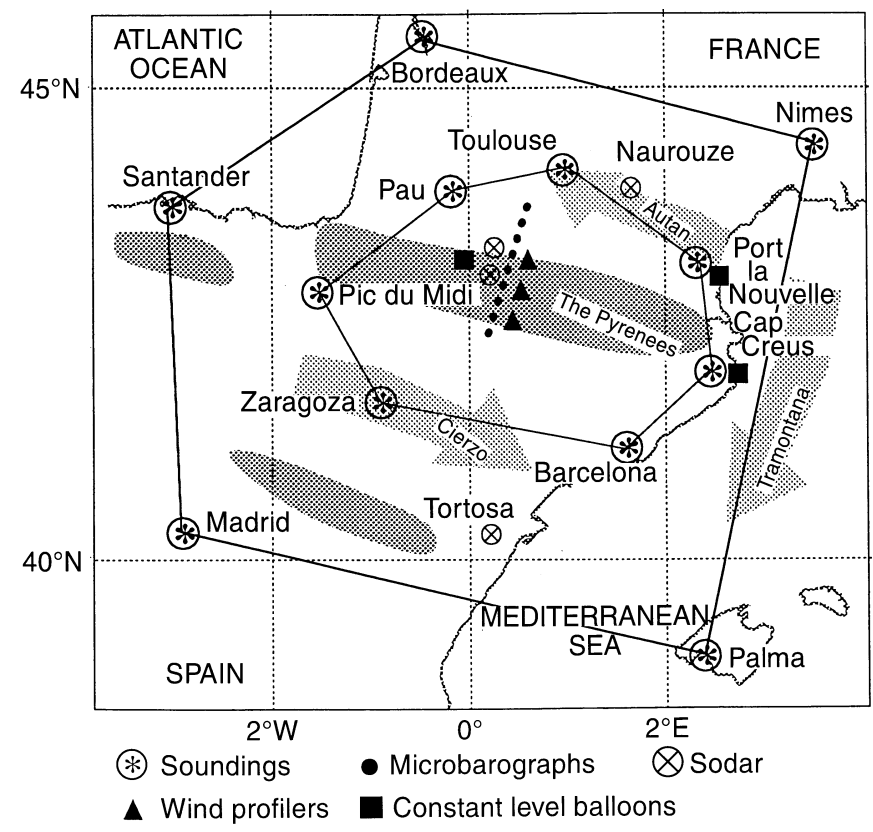

Fig. 1. Synoptic view of the ground infrastructure during PYREX. Different local winds indicated by large shaded arrows (after Bougeault et al., 1993) data for numerical models. Three ST radars gave continuous measurement of the wind profile on both sides of the mountain chain. Numerous ground stations and some sodars had been set out around the chain and along a cross section perpendicular to the Pyrenees. The sodars and the ground stations studied the dynamics of the local boundary layers (e.g., valley winds) and constant volume balloons were launched to study gravity waves and deflected flows around the Pyrenees. To complement these, four aircraft were used during the PYREX experiment: a Falcon 20 of Deutsche Forschungsanstalt für Luft- und Raumfahrt (DLR), a Fokker 27, instrumented by the Institut National des Sciences de l'Univers (INSU), a Fairchild Merlin IV and a Piper-Aztec, instrumented by Météo-France.

\section{Aircraft}

Among the four research aircraft measurements, only those of the Falcon and Fokker are used here to describe the mountain wave events. Both aircraft have the same capabilities for measuring atmospheric turbulence. They measure turbulent and mean parameters such as temperature, water vapor content, horizontal components of the wind and the fluctuations of the vertical velocity of the air. The Falcon and the Fokker are each equipped with a nose boom (1.8 $\mathrm{m}$ and $6 \mathrm{~m}$ long respectively) tipped with fast-response sensors. They consist of a Rosemount 858 probe, which measures static and dynamic pressures, and the attack and sideslip angles. On the Fokker 27, an inertial navigation system (INS) (Sagem ULIS 45i), installed close to the gravity center of the aircraft, measures the aircraft's horizontal geographical position, the ground velocity vector and the attitude angles of the aircraft (pitch, roll and true heading). The airspeed of the Fokker is about $80 \mathrm{~m} \mathrm{~s}^{-1}$ and the data are recorded at the rate of $16 \mathrm{~s}^{-1}$. Thus, the spatial resolution of turbulence data is about $5 \mathrm{~m}$. The wind vector is calculated with a classical algorithm, from measurements of dynamic pressure, attack and sideslip angles, and ground velocity vector provided by the INS (see for instance Lenschow, 1986). The Falcon 20 has an inertial reference system (IRS) (Honeywell Lasernav YG 1779) which is located about $5.8 \mathrm{~m}$ behind the tip of the nose boom. The equipment of the Falcon 20 is described in detail by Bögel and Baumann (1991). The airspeed of the Falcon reaches $200 \mathrm{~m} \mathrm{~s}^{-1}$ and the sampling rate is $100 \mathrm{~s}^{-1}$, which gives a spatial resolution of $2 \mathrm{~m}$. The 10 straight and level runs performed by the two aircraft during a mountain wave event, are described in Fig. 2. During a wave event, the Fokker performed 4 straight and level runs at altitudes between 4 and $6 \mathrm{~km}$ whereas the Falcon performed 6 in the same time at altitudes between 8 and $12 \mathrm{~km}$, following a ground track between Auch $\left(43.8^{\circ} \mathrm{N}, 0^{\circ} \mathrm{E}\right.$; France) and Huesca $\left(43.6^{\circ} \mathrm{N}, 0.6^{\circ} \mathrm{E}\right.$; Spain). The mean duration of a run for the Fokker and the Falcon is about $40 \mathrm{~min}$ and $20 \mathrm{~min}$, respectively. All the flight periods began at 06:00 UT except for 15 November (at 12:00 UT). 


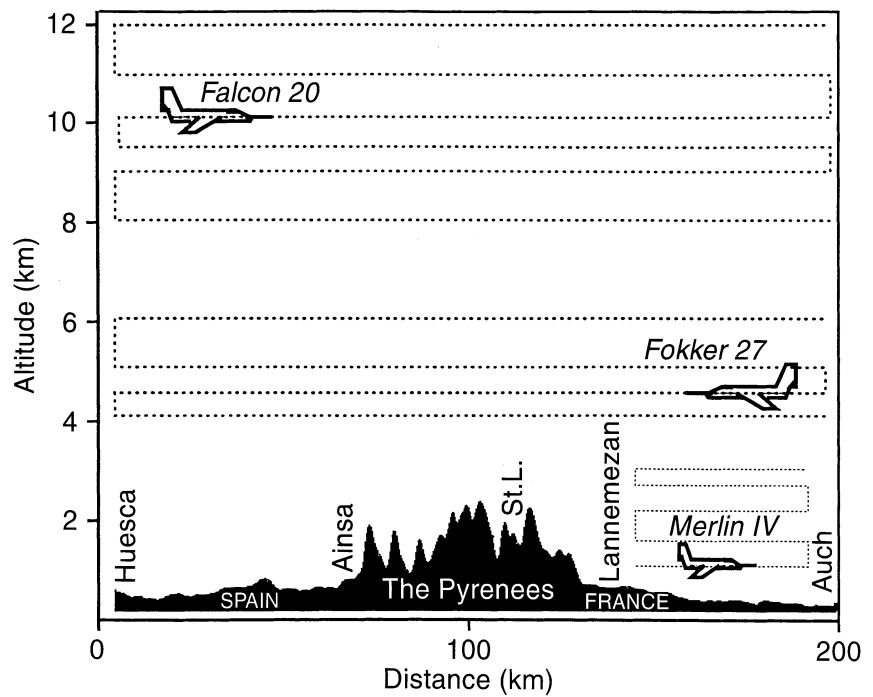

Fig. 2. Flight plan of the aircraft for a mountain wave event during the PYREX experiment. The 6 upper runs (altitude between 8 and $12 \mathrm{~km}$ ) were performed by the Falcon 20, the 4 runs between 4 and $6 \mathrm{~km}$ of altitude were performed by the Fokker 27. On the downwind side of the mountain, the Merlin IV ran several legs perpendicular and parallel to the Pyrenees main axis over France for a southerly flow and over Spain for a northerly flow. The shaded area represents the mountain relief measured by the Fokker 27 during its lowest altitude run

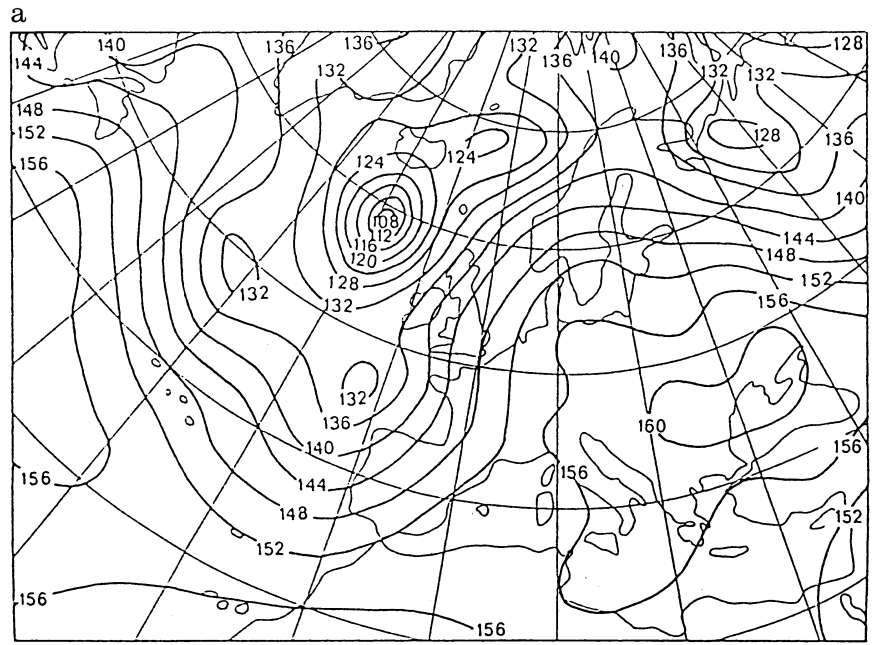

c

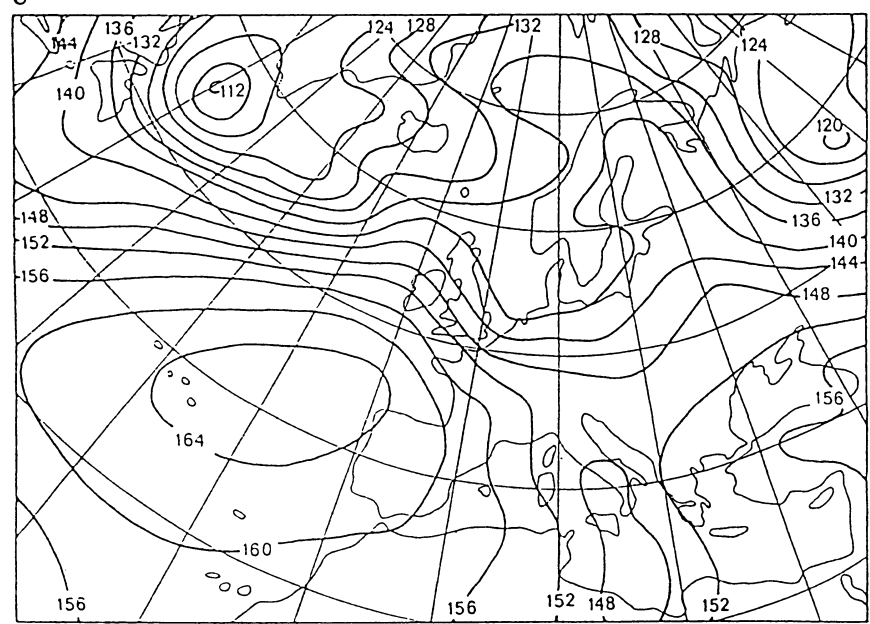

\section{The meteorological situation}

\subsection{Synoptic fields at $850 \mathrm{hPa}$}

Figure 3a shows the $850 \mathrm{hPa}$ synoptic map on 15 October 1990 at 00:00 UT. The large low-pressure zone located over the Atlantic Ocean has a minimum extending from the north of Ireland to the NW of Spain and a high pressure zone was located near the Black sea. The low-pressure zone induced a strong $\mathrm{S}$ to SW wind over Spain and southern France, almost perpendicular to the Pyrenees chain. A cold front connected with the pressure minimum reached the French coast at about 12:00 UT. Near the Pyrenees, the isohypses at $850 \mathrm{hPa}$ were nearly perpendicular to the mountain chain from 00:00 UT to 12:00 UT, which includes the measurement period. The pressure gradient along the axis of the Pyrenees was about $4 \mathrm{hPa} / 100 \mathrm{~km}$. Figure $3 \mathrm{~b}, \mathrm{c}, \mathrm{d}$ shows the evolution of the synoptic meteorological situation from 14 November to 16 November at 00:00 UT. The westerly synoptic flow over France was driven by a low-pressure zone, located over the north of the Atlantic Ocean and Europe, and the Azores anticyclone located to the west of Spain. On 14 November, the low-pressure zone, extending over the

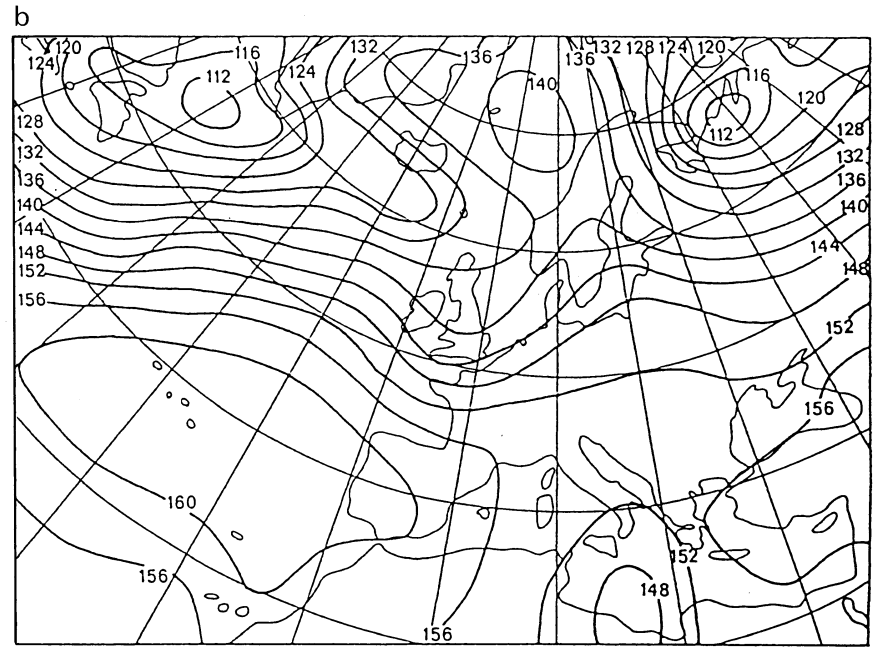

d

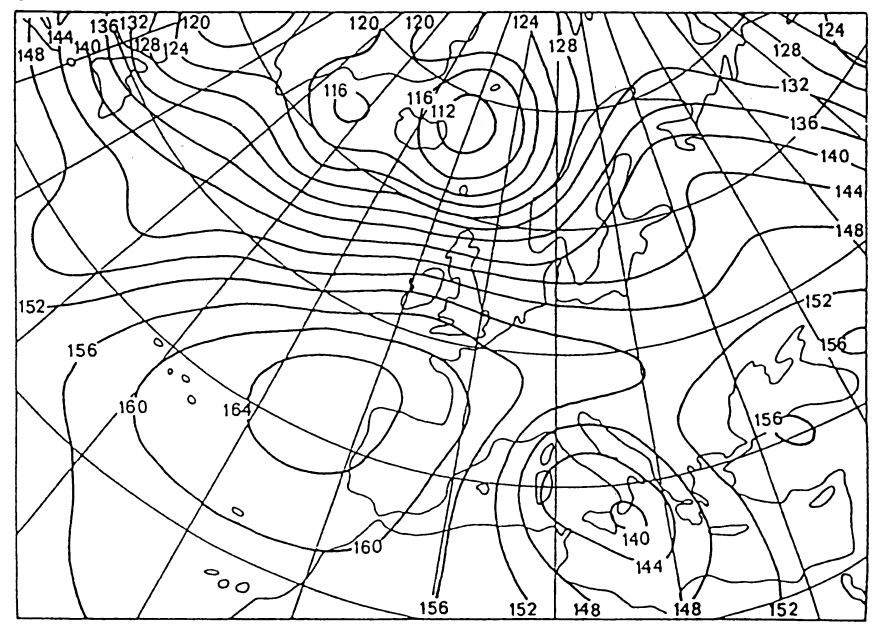

Fig. 3a-d. Synoptic field of the geopotential (in tens of meters) at $850 \mathrm{hPa}$ for the 4 mountain wave cases: a 15/10/90; b 14/11/90; c 15/11/90; d 16/11/90 at 00:00 UT 
Mediterranean Sea south of Italy, generated over the western Mediterranean Sea a northerly flow which became more intense on 15 November and even 16 . Above the Pyrenees, the synoptic flow was westerly on 14 November at 00:00 UT and was driven by the two low-pressure zones located to the north and over the Mediterranean Sea. On 15 November at 00:00 UT, the low-pressure zone over the Mediterranean Sea was more active and was located more to the north than on 14 November. This low-pressure zone drove a northerly synoptic flow above the Pyrenees and over the western Mediterranean Sea. On 16 November at 00:00 UT, the synoptic flow above the Pyrenees generated a strong northerly wind varying from 10 to $20 \mathrm{~m} \mathrm{~s}^{-1}$. The synoptic flow evolved during the three days from $\mathrm{W}$ NW, nearly parallel to the axis of the Pyrenees chain, to north, i.e., perpendicular to the chain.

\subsection{The wind and temperature field at $600 \mathrm{hPa}$ and $200 \mathrm{hPa}$}

The Peridot model analysis of Météo-France (Bougeault and Mercusot, 1992) gathers all the avalaible large-scale data and the specific data of each PYREX situation. The horizontal size of the mesh grid is $35 \mathrm{~km} \times 35 \mathrm{~km}$. $600 \mathrm{hPa}$ and $200 \mathrm{hPa}$, corresponding to the lowest and highest level flown by the aircraft, are representative of the mean troposphere and of the troposphere-strato-
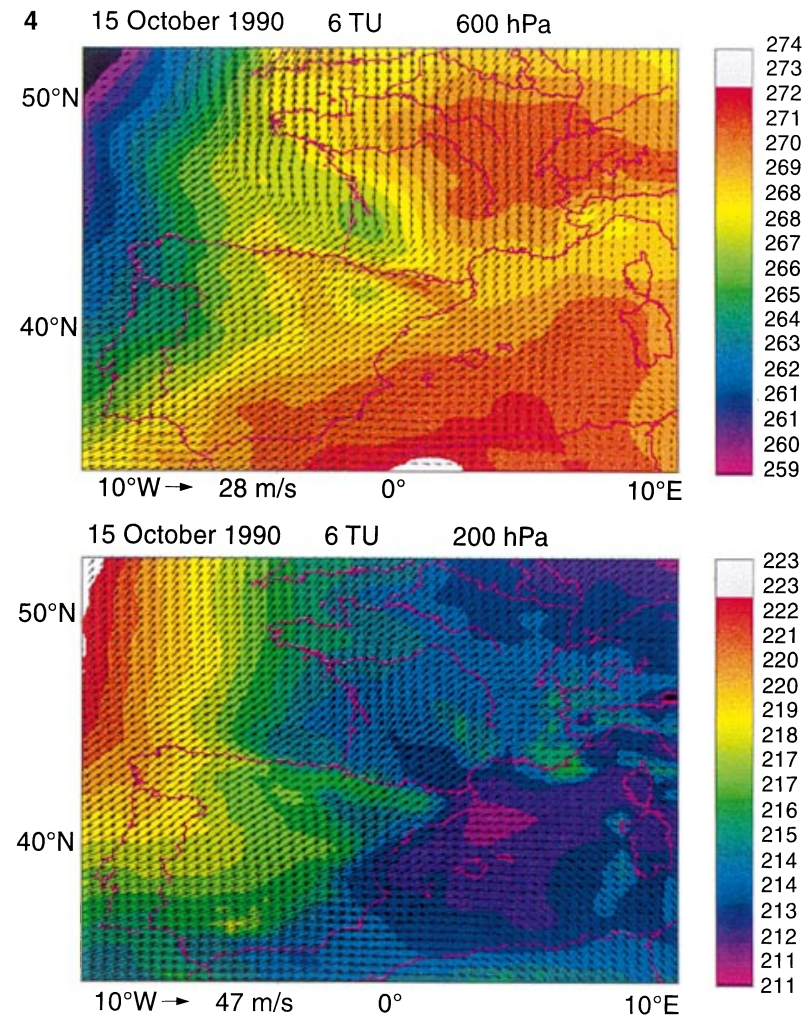

Fig. 4. Isolevels of temperature (colors, in $\mathrm{K}$ ) and horizontal wind (arrows) at $600 \mathrm{hpa} \mathrm{(top)} \mathrm{and} 200 \mathrm{hPa}$ (bottom) for 15 October 1990 at 06:00 UT (from Peridot Analysis of Météo-France). The wind scale is given by the maximum of the field under each graph sphere transition, respectively. We present in Fig. 4 the temperature (colors) and the horizontal wind (arrows) for 15 October. That day was characterized by an airflow from the SW. At $600 \mathrm{hPa}$, the airflow was perturbed in the vicinity of the Pyrenees chain, and slowed down on the lee side of the mountain. The southerly warm air spread out over France whereas the Atlantic Ocean was colder. At $200 \mathrm{hPa}$, the wind was westerly and the warm zones were situated over the Atlantic Ocean. The meteorological situations of 14, 15 and 16 November, correspond to the northerly wave events are also presented in Figs. 5 and 6. At $600 \mathrm{hPa}$ (Fig. 5), the wind velocity was nearly constant and the direction turned from NW on 14 November to due $\mathrm{N}$ on 16 November with an important perturbation above the Pyrenees. At $200 \mathrm{hPa}$ (Fig. 6), the warmer zone, located to the north of the domain on 14 November extended
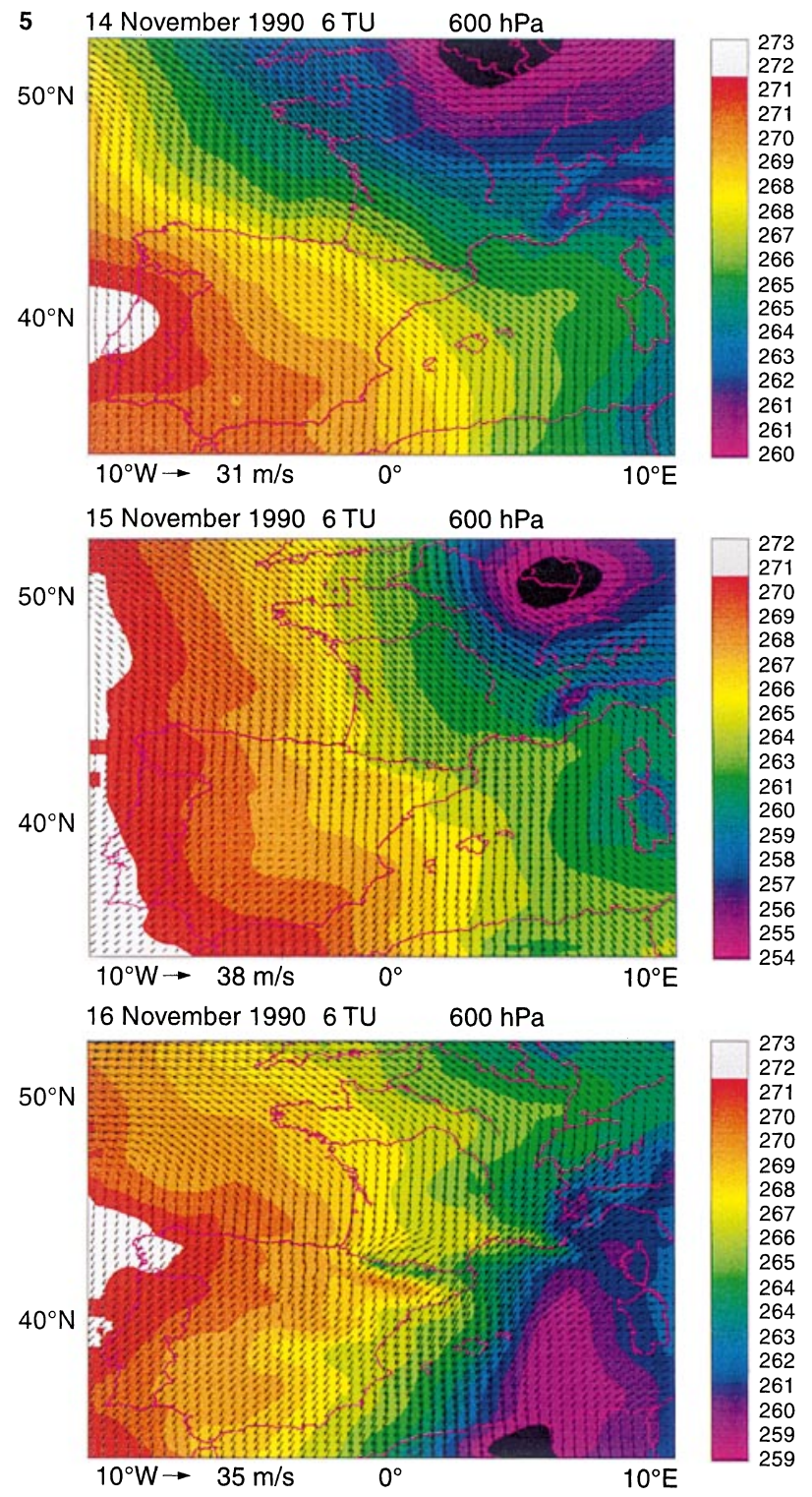

Fig. 5. Same as Fig. 4 but for 14, 15 and 16 November 1990 at $600 \mathrm{hPa}$ 
614 November $19906 \mathrm{TU} \quad 200 \mathrm{hPa}$

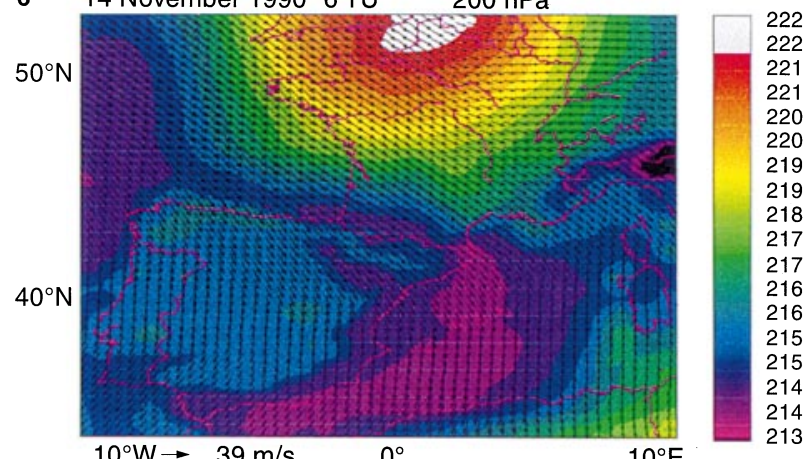

15 November $19906 \mathrm{TU} \quad 200 \mathrm{hPa}$
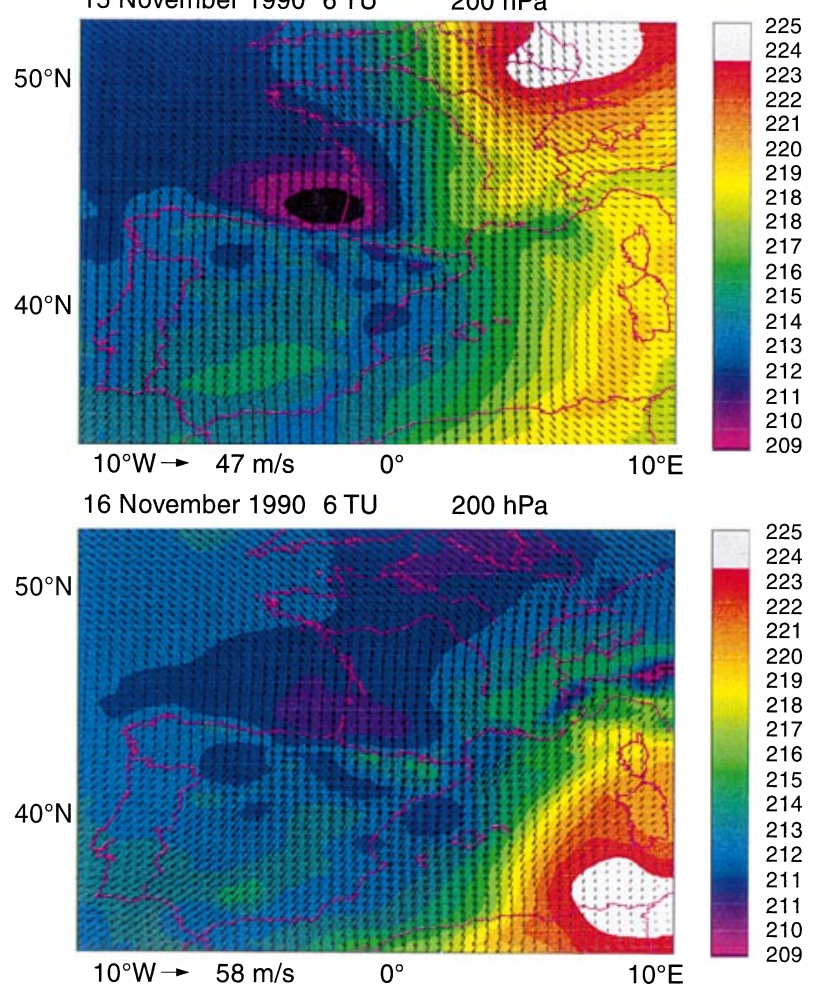

Fig. 6. Same as Fig. 5 but at $200 \mathrm{hPa}$

eastwards on 15 November and finally towards the SE on 16 November.

\section{Upstream characteristics}

The upstream conditions are characterized by the radiosonde soundings at Zaragoza on 15 October at 06:00 UT, and at Toulouse on 14 November at 12:00 UT, 15 November at 06:00 UT and 16 November at 06:00 UT (Figs. 7 to 10). The profile at Zaragoza was moister than those at Toulouse. It showed a saturated zone between $800 \mathrm{hPa}$ and $500 \mathrm{hPa}$ corresponding to an upstream cloudy zone which grew during the period of aircraft flights. Under $600 \mathrm{hPa}$, the wind speed reached $17 \mathrm{~m} \mathrm{~s}^{-1}$ and the direction was $227^{\circ}$ at about $700 \mathrm{hPa}$. The radiosonde soundings at Toulouse were not saturated except on 14 November which presents a saturated zone between the ground and $700 \mathrm{hPa}$. At about $700 \mathrm{hPa}$, the wind direction measured at Toulouse turned from $328^{\circ}$ to $360^{\circ}$ respectively on 14 November

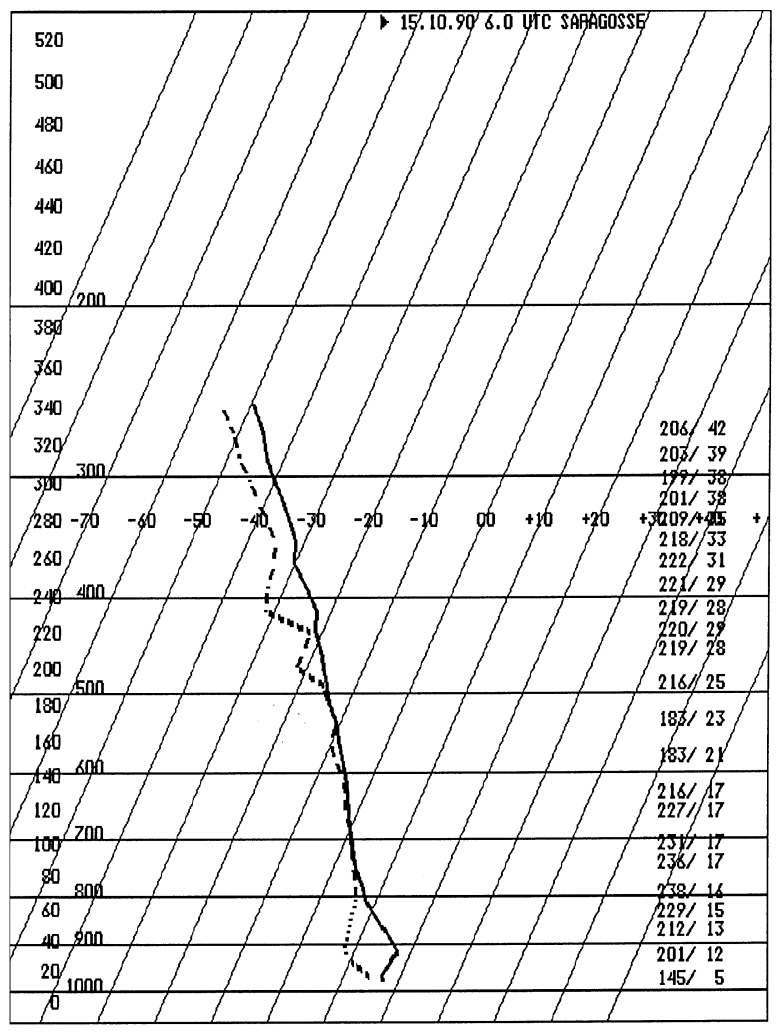

Fig. 7. Upstream profiles from radiosonde soundings: 15 October, 06:00 UT at Zaragoza. Temperature (solid line) and dewpoint temperature (dashed line). The arrows show the height of the tropopause. The values on the right side of each graph represent the direction (in degrees) and the wind-speed (in $\mathrm{m} \mathrm{s}^{-1}$ ) respectively. The values on the left border represent the altitude in hundreds of feet. A horizontal line is drawn each $100 \mathrm{hPa}$. The oblique lines represent the temperature iso-values ${ }^{\circ} \mathrm{C}$

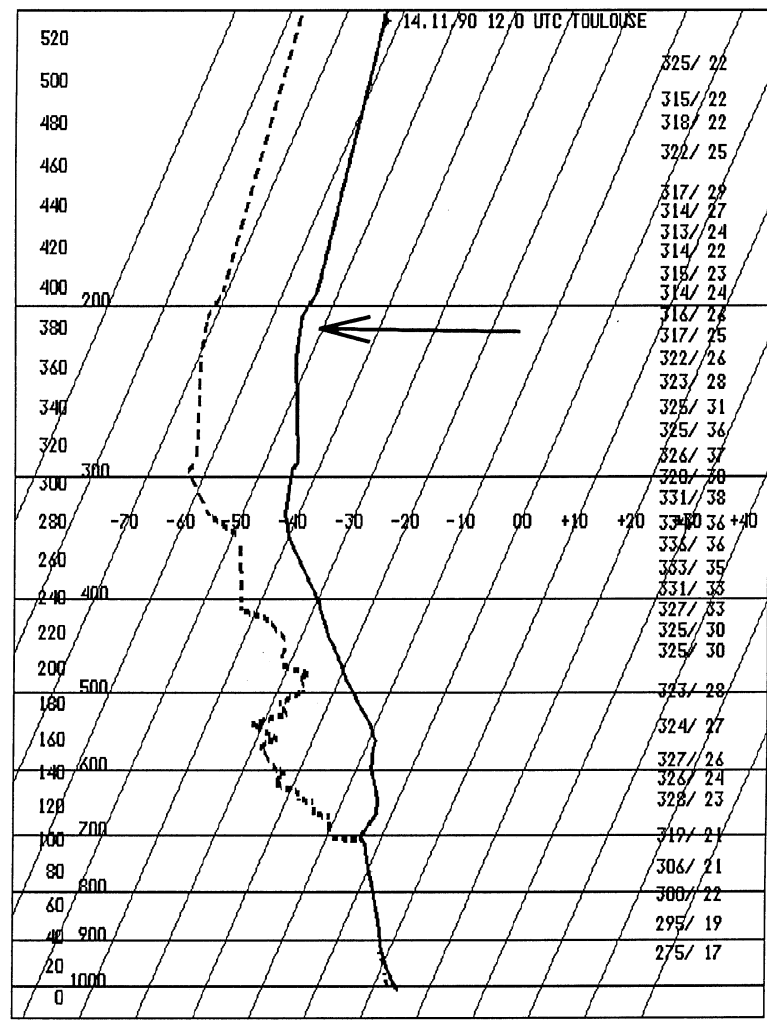

Fig. 8. Same as Fig. 7, but for 14 November, 12:00 UT at Toulouse 


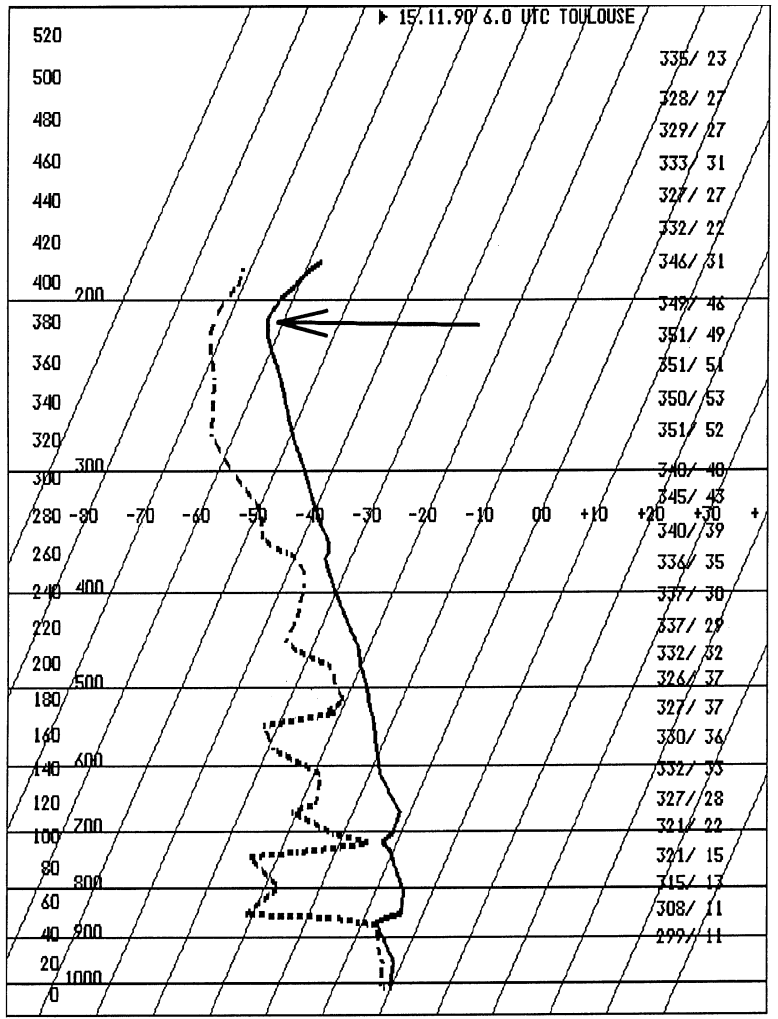

Fig. 9. Same as Fig. 8, but for 15 November at 06:00 UT

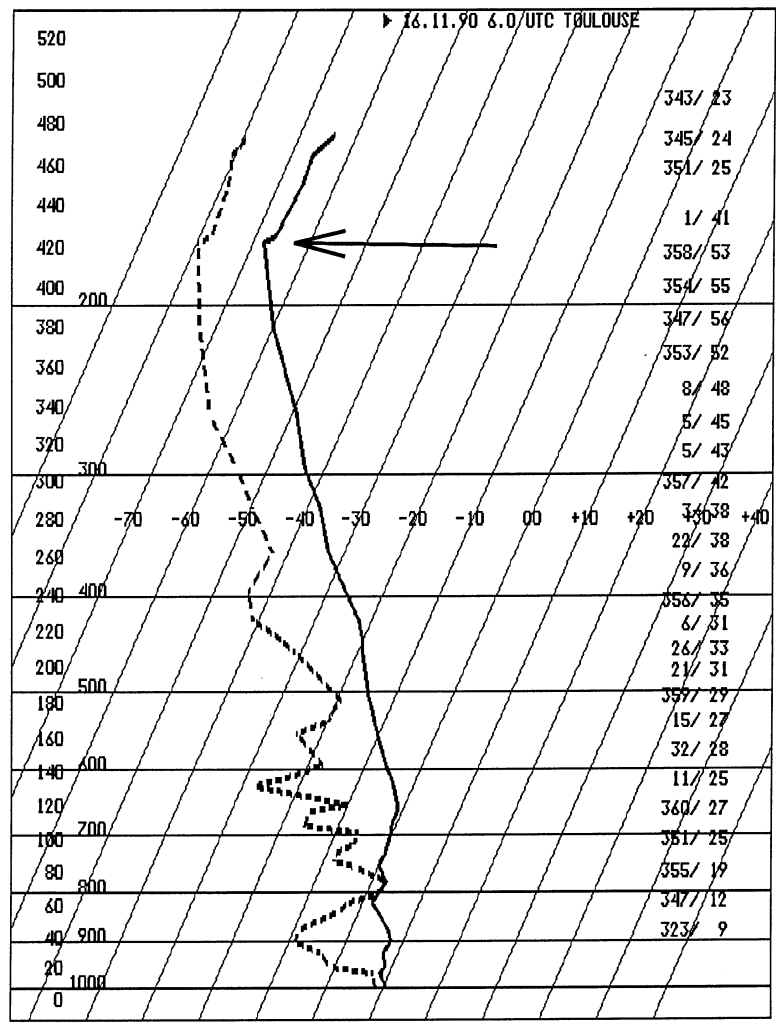

Fig. 10. The same as Fig. 8, but for 16 November at 06:00 UT and 16 November (for more details, see Table 1). The radiosonde soundings determine the reference upstream conditions and permit calculation of the characteristic data for the airflow. The mountain wave mechanism depends on the upstream lapse rate and wind profile. These two parameters can be combined to compute the Brunt Väisälä frequency and the Froude number. The Brunt Väisälä frequency evaluates the oscillation frequency of the air parcel and the Froude number represents the ratio of the inertial to the buoyancy force. The Brunt Väisälä frequency is defined as:

$N=\left(\frac{g}{T} \frac{\partial \theta}{\partial z}\right)^{\frac{1}{2}}$

where $g$ is gravity and $T$ and $\theta$ the temperature and the potential temperature of the air, respectively. The corresponding wavelength is:

$\lambda=2 \pi \frac{U}{N}$

where $U$ is the horizontal wind speed. We also define the Froude number as:

$F r=\frac{U}{N h}$

where $h$ is the average height of the mountain. Table 1 presents the principal parameters calculated from the upstream data of the four wave events. We remark that the $\mathrm{Fr}$ on 15 October is greater than on the other days. Thus, the mountain wave amplitude of the southerly flow case should be more important than that of the northerly ones. Moreover $\lambda$ predicts lee waves with a wavelength of about $10 \mathrm{~km}$, not studied in the present work. The lee waves on 15 October have already been studied by Bénech et al. (1994) and Tannhauser and Attié (1995).

\section{The southerly flow example above the Pyrenees}

The 2D fields studied in the following sections represent a plane $200 \mathrm{~km}$ long (abscissa) and $8 \mathrm{~km}$ high (between 4 and $12 \mathrm{~km}$ in altitude). On the horizontal axis, the top of the Pyrenees chain is located in the middle of the axis, i.e at the abscissa of $100 \mathrm{~km}$. The left border of the diagram represents $\mathrm{S}$ and the right border $\mathrm{N}$. The method of interpolation for aircraft data is presented in Appendix A.

\subsection{The dynamical and thermodynamical variables}

The horizontal wind component perpendicular to the Pyrenees chain (Fig. 11a) presents, between at 6 and $8 \mathrm{~km}$ altitude, a zone of weak horizontal gradient, which separates two distinct zones: the first, at lower altitudes, shows an acceleration of the wind when the flow crosses the mountain (the wind strength varies from $14 \mathrm{~m} \mathrm{~s}^{-1}$ to $22 \mathrm{~m} \mathrm{~s}^{-1}$ ), followed by a weak deceleration downstream where the wind strength falls to $18 \mathrm{~m} \mathrm{~s}^{-1}$. The second lies between 10 and $12 \mathrm{~km}$ altitude, where a minimum 
Table 1. Upstream characteristics deduced from radiosonde soundings: Brunt Väisälä wavelength $(\lambda)$, Froude number $(F r)$, speed of horizontal wind vector $(U)$ and its angle with the cross-chain axis $(D D)$ (the sign is positive in the clockwise sense). The values were computed in the $3000-6000 \mathrm{~m}$ altitude range except for $F r$ computed in $0-3000 \mathrm{~m}$ range and $D D$ measured at about $3000 \mathrm{~m}$

\begin{tabular}{llrlll}
\hline Date & Sounding & $\lambda(\mathrm{m})$ & $F r$ & $U\left(\mathrm{~m} \mathrm{~s}^{-1}\right)$ & $D D$ (degrees) \\
\hline 15.10 .90 & Zaragoza 06:00 UT & 9200 & 0.9 & 20 & 27 \\
14.11 .90 & Toulouse 12:00 UT & 10700 & 0.3 & 25 & $-52(+180)$ \\
15.11 .90 & Toulouse 06:00 UT & 13800 & 0.5 & 32 & $-53(+180)$ \\
16.11 .90 & Toulouse 06:00 UT & 10800 & 0.3 & 27 & $-20(+180)$ \\
\hline
\end{tabular}

speed wind $\left(26 \mathrm{~m} \mathrm{~s}^{-1}\right)$, associated with the potential temperature oscillation described later, corresponds to an important deceleration of the airmass. The mean vertical velocity of the air was calculated by three different methods (see Appendix B). The vertical velocity is obtained from the steady-state equation for the conservation of temperature. The vertical velocity (Fig. 11b) shows extrema which propagate vertically and slightly backwards. The downward velocities reach $-0.4 \mathrm{~m} \mathrm{~s}^{-1}$ just above the mountain at lower altitudes. This, downward movement was confirmed by constant volume balloon trajectories (Hammam, 1991) and is associated with the principal perturbation seen on the temperature field. Downstream, we also observe a second oscillation at higher altitudes, corresponding to that observed on the potential temperature field, with a velocity varying from $-1.2 \mathrm{~m} \mathrm{~s}^{-1}$ to $+1.8 \mathrm{~m} \mathrm{~s}^{-1}$.

The potential temperature field (Fig. 11c) shows a stable stratification with a mean vertical gradient of $0.4{ }^{\circ} \mathrm{C} / 100 \mathrm{~m}$ at altitudes between 4 and $12 \mathrm{~km}$. This field is characterized by a large wave just above the mountain extending between $80 \mathrm{~km}$ and $120 \mathrm{~km}$ on the horizontal axis. This perturbation due to the relief, hereafter called "principal perturbation", propagates slightly backwards with the altitude. It corresponds to an increase in temperature of about $2{ }^{\circ} \mathrm{C}$. Above the $8 \mathrm{~km}$ altitude, the principal perturbation is followed by a large oscillation with a horizontal dimension of about
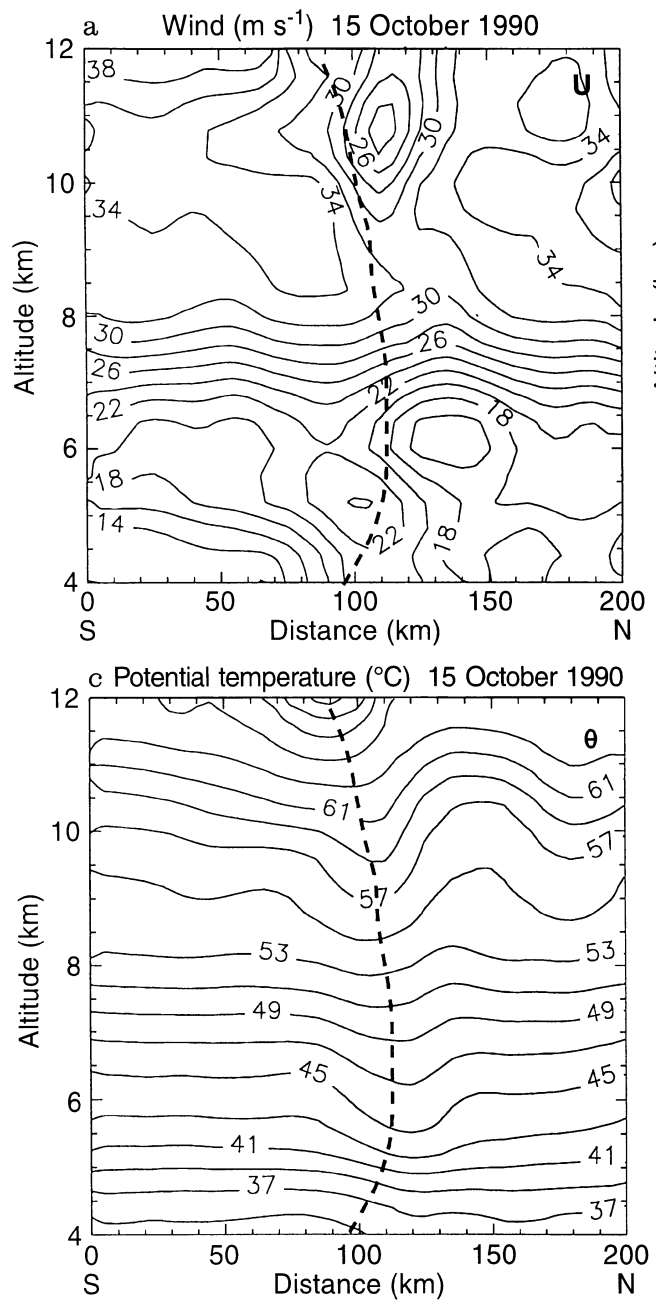
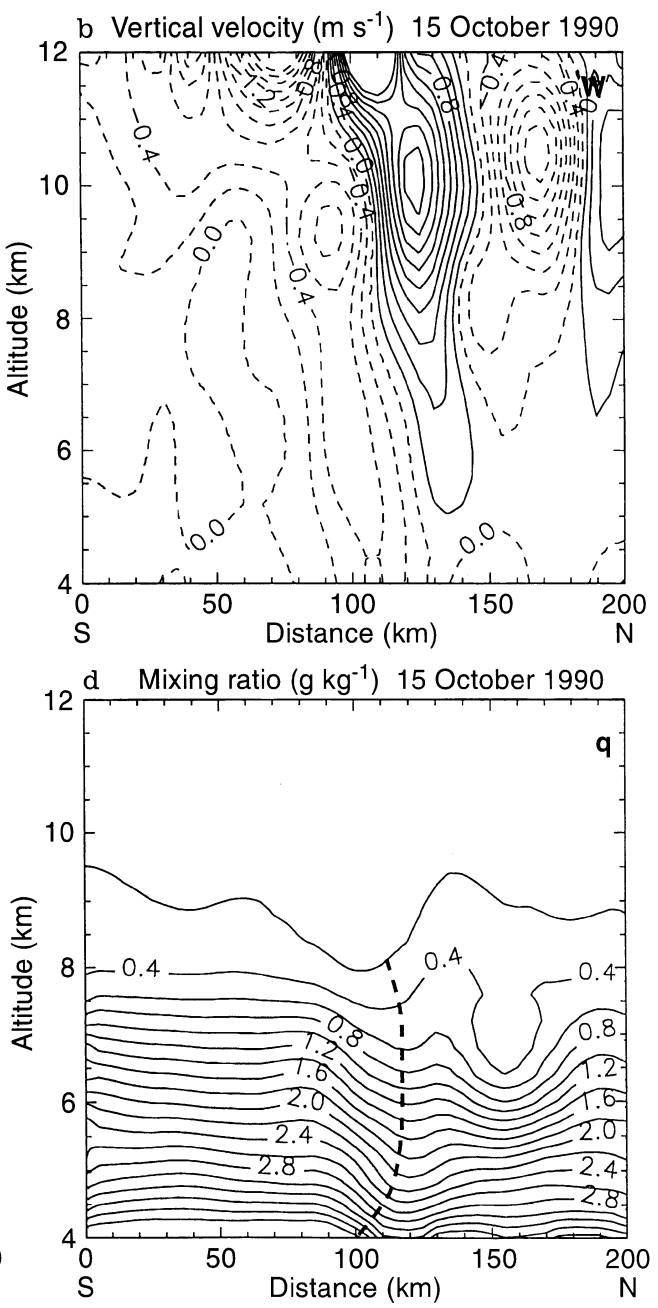

Fig. 11a-d. Characteristics of the 15 October event in the crosschain vertical plane: horizontal wind cross-chain component a vertical velocity; b both in $\mathrm{m} \mathrm{s}^{-1} ; \mathbf{c}$ potential temperature in ${ }^{\circ} \mathrm{C}$; $\mathbf{d}$ and moisture in $\mathrm{g} \mathrm{kg}^{-1}$. On graph $\mathbf{b}$ the dashed lines correspond to downward velocities and the solid lines to upward velocities. The heavy dashed lines on $\mathbf{a}, \mathbf{c}, \mathbf{d}$ show the position of the mountain wave 
$50 \mathrm{~km}$ and an amplitude between 4 and $5{ }^{\circ} \mathrm{C}$. The specific humidity field (Fig. 11d) shows a vertical gradient of about $-1 \mathrm{~g} \mathrm{~kg}^{-1} \mathrm{~km}^{-1}$, located on the principal perturbation, at an altitude between 4 and $7 \mathrm{~km}$. As for the potential temperature, there is a specific humidity perturbation on the lee side of the mountain. This perturbation corresponds to a drying effect of $0.8 \mathrm{~g} \mathrm{~kg}^{-1}$ which remains downstream in the analyzed domain. In this region, we observe an oscillation associated with that observed on the potential temperature and wind velocity. The difference in specific humidity between the downwind and upwind edges of the domain is between 0 and $-0.5 \mathrm{~g} \mathrm{~kg}^{-1}$, showing a global drying of the airmass. The combination of the dynamical and thermodynamical effects clearly shows a deceleration at upper altitudes and a feed-in of warm air, probably coming from the stratosphere, associated with a global drying of the airmass at lower altitudes.

\subsection{Horizontal advection terms}

To quantify the different thermodynamical and dynamical effects encountered above the Pyrenees chain, we compute the horizontal advection terms of the budget equation for the wind $(\bar{u} \partial \bar{u} / \partial x)$, the temperature $(\bar{u} \partial \bar{\theta} / \partial x)$ and the specific humidity $(\bar{u} \partial \bar{q} / \partial x)$, where $x$ is the horizontal coordinate parallel to the cross section and the overbar designates the horizontal average over a $10 \mathrm{~km}$ box. As mentioned the phenomena are presumed to be steady and two-dimensional and therefore only dependent on the altitude $z$ and the horizontal coordinate $x$. We thus have the following simplified equation for the horizontal wind:

$\bar{u} \frac{\partial \bar{u}}{\partial x}+\bar{w} \frac{\partial \bar{u}}{\partial z}=-\frac{\partial}{\partial z}\left(\overline{u^{\prime} w^{\prime}}\right)+f \bar{v}-\frac{1}{\bar{\rho}} \frac{\partial \bar{p}}{\partial x}$

where $f$ is the Coriolis parameter, $\bar{p}$ the pressure and $\bar{\rho}$ the density of the air; $\bar{u}$ and $\bar{v}$ represent the horizontal components of the wind perpendicular and parallel to the mountain chain respectively; $\bar{w}$ is the vertical velocity of the air. The horizontal advection term $\bar{u} \partial \bar{u} / \partial x$ (Fig. 12a) is similar to the Lagrangian acceleration of the air parcel. At lower altitudes, this term is positive with a maximum value of about $3 \times 10^{-3} \mathrm{~m} \mathrm{~s}^{-2}$ and corresponds to the acceleration of the airflow near the relief. Downstream, it becomes negative in a vertical domain at an altitude between $10 \mathrm{~km}$ and $12 \mathrm{~km}$ with a minimum of $-1 \times 10^{-2} \mathrm{~m} \mathrm{~s}^{-2}$. This area follows the vertical wave observed on the potential temperature field. The horizontal advection term allows us to show better the wave mechanism above the mountain and to quantify the acceleration of the airflow. The maximum values of transverse wind, between $-10 \mathrm{~m} \mathrm{~s}^{-1}$ and $+10 \mathrm{~m} \mathrm{~s}^{-1}$ give corresponding values of the Coriolis term $(f \bar{v})$ between $-10^{-3}$ and $+10^{-3} \mathrm{~m} \mathrm{~s}^{-2}$. The Coriolis term can be compared to the horizontal advection term. In the perturbed zone near the relief, the local values of horizontal advection term reach $-10^{-2} \mathrm{~m} \mathrm{~s}^{-2}$ and are 10 times the Coriolis term. However, the Coriolis term has to be compared to the
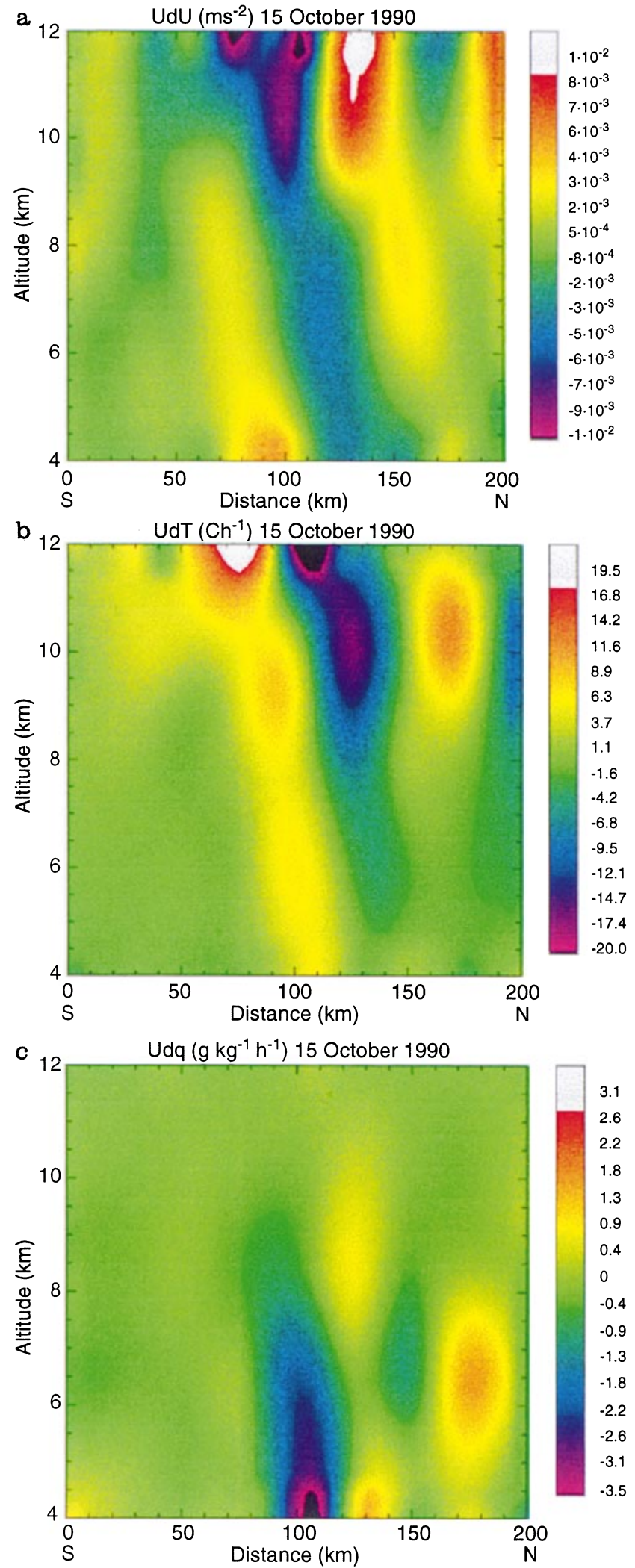

Fig. 12. a horizontal advection of wind (in $\mathrm{m} \mathrm{s}^{-2}$ ); $\mathbf{b}$ of potential temperature (in ${ }^{\circ} \mathrm{C} \mathrm{h}^{-1}$ ) and $\mathbf{c}$ of specific humidity (in $\mathrm{g} \mathrm{kg}^{-1} \mathrm{~h}^{-1}$ ) for the 15 October event 
global acceleration computed at the scale of the domain. This acceleration is defined as $\Gamma=\bar{U}\left(U_{2}-U_{1}\right) / \Delta x$, where $\bar{U}$ is the average wind at a given altitude, $U_{1}$ and $U_{2}$ are the upstream and the downstream wind respectively at the same altitude. The values obtained on the $\Gamma$ profile vary between $-3 \times 10^{-3}$ and $3 \times 10^{-3} \mathrm{~m} \mathrm{~s}^{-2}$ and are of the same order of magnitude as the Coriolis term. This result shows that the Coriolis term is not negligible compared to the global acceleration of the orographic airflow.

None of the large-scale parameters can be compared to the horizontal advection term of temperature and moisture. The latter terms express a heating rate (in ${ }^{\circ} \mathrm{C} \mathrm{h}^{-1}$ ) and a moistening rate (in $\mathrm{g} \mathrm{kg}^{-1} \mathrm{~h}^{-1}$ ) respectively. The horizontal advection of temperature (Fig. 12b) presents a wave structure above the Pyrenees within the region extending from the top of the mountains, to the upper boundary of the domain. At the highest altitudes, between 10 and $12 \mathrm{~km}$ on the lee side of the mountains, the oscillation corresponds to that observed on the potential temperature and wind fields. Just above the Pyrenees, the values of the horizontal advection of temperature are larger (about $10{ }^{\circ} \mathrm{C} \mathrm{h}^{-1}$ ), which correspond to a heating of the air parcel. The horizontal advection of moisture (Fig. 12c) is only discussed in the lower part of the domain at altitudes between 4 and $7 \mathrm{~km}$ and also presents a wave structure with a minimum of $-2.5 \mathrm{~g} \mathrm{~kg}^{-1} \mathrm{~h}^{-1}$ just above the Pyrenees chain (abscissa $100 \mathrm{~km}$ ), corresponding to a drying of the airflow. We can compare these two terms of advection to a heating rate or a moistening rate for a typical homogeneous convective boundary layer, $1000 \mathrm{~m}$ thick, with surface latent and sensible heat fluxes of $200 \mathrm{~W} \mathrm{~m}^{-2}$ each. Assuming there is no entrainment (i.e., the fluxes vanish at the top of the boundary layer), we obtain a heating rate of $+0.7{ }^{\circ} \mathrm{C} \mathrm{h}^{-1}$ and a moistening rate of $+0.3 \mathrm{~g} \mathrm{~kg}^{-1} \mathrm{~h}^{-1}$. This example shows that the PYREX values of horizontal advection of temperature and moisture observed in the mountain wave area are one order of magnitude greater than those encountered in a convective boundary layer.

\subsection{Turbulent terms}

Table 2 presents typical values of turbulent parameters measured in stably stratified and convective boundary layers. We present the standard deviation of the vertical velocity $\left(\sigma_{w}\right)$, the sensible heat flux $\left(H=\rho C_{p} \overline{w^{\prime} \theta^{\prime}}\right)$, the dissipation rate of TKE $(\epsilon)$ and the inertial length-scale defined as $l_{\epsilon}=\sigma_{w}^{3} / \epsilon$. These parameters will be compared with those obtained above the Pyrenees chain. There are a few papers which describe high altitude turbulence data associated with an orographic airflow. For example, Lilly and Zipser (1972) have presented an altitude turbulence linked to a large oscillation above the Rocky Mountains.

In this section, we first present the fields of turbulent momentum flux $\left(\rho \overline{u^{\prime} w^{\prime}}\right)$ and sensible heat flux computed by the eddy-correlation and the inertial-dissipation methods. The eddy-correlation method has been applied to $20 \mathrm{~km}$ long samples, high-pass filtered with a cut-off wavelength of $1500 \mathrm{~m}$. The inertial-dissipation method is explained in Appendix C. On the graphs, the flux fields are superimposed on mean variable fields (potential temperature for $H$ and wind for momentum). At lower altitudes (about $4 \mathrm{~km}$ ), some boundary effects appear on fields obtained by the inertial-dissipation method, due to the computation of the wind and temperature gradient. However, the flux fields, calculated using both methods, present a similar shape with the same orders of magnitude showing a heterogeneous and sporadic turbulence. The field of momentum flux (Fig. 13) shows negative values in the lower part of the field, showing that the deceleration of the airflow is associated with a downward momentum transfer of less than $-0.16 \mathrm{~N} \mathrm{~m}^{-2}$. The positive maximum is located at $70 \mathrm{~km}$ downstream of the top of the mountain (abscissa $170 \mathrm{~km}$ ) at an altitude of $11 \mathrm{~km}$ in a wind negative gradient linked to the altitude oscillation. The end of the altitude oscillation is thus associated with an upward momentum flux of about $0.1 \mathrm{~N} \mathrm{~m}^{-2}$. The field of sensible heat flux (Fig. 14) presents a negative maximum (less than $-12 \mathrm{~W} \mathrm{~m}^{-2}$ ) at the end of the altitude oscillation showing a downward heat transfer. Moreover, at lower altitudes (about $4 \mathrm{~km}$ ), the field shows a
Table 2. Characteristic values of various turbulence parameters measured in stably stratified boundary layer, convective boundary layer and during PYREX: standard deviation of vertical velocity $\left(\sigma_{w}\right)$, sensible heat flux $(H)$, dissipation rate of TKE $(\epsilon)$ and inertial length-scale $\left(l_{\epsilon}\right)$

\begin{tabular}{lllll}
\hline & $\sigma_{w}\left(\mathrm{~m} \mathrm{~s}^{-1}\right)$ & $H\left(\mathrm{~W} \mathrm{~m}^{-2}\right)$ & $\epsilon\left(\times 10^{-4} \mathrm{~m}^{2} \mathrm{~s}^{-3}\right)$ & $l_{\epsilon}(\mathrm{m})$ \\
\hline $\begin{array}{l}\text { Druilhet et al. (1989): stably stratified BL } \\
\text { Marine boundary layer }\end{array}$ & 0.20 & -20 & 12 & 6.5 \\
$\begin{array}{l}\text { Convective boundary layer (CBL) } \\
0.02 Z_{i}\end{array}$ & 0.28 & +13 & 34 & 6.5 \\
$0.23 Z_{i}$ & 0.69 & +140 & 61 & 54 \\
$0.71 Z_{i}$ & 1.24 & +117 & 36 & 530 \\
$1.1 Z_{i}$ & 0.81 & -5 & 32 & 166 \\
Caughey et al. (1979): stably stratified BL & - & -2 & 0.75 & 360 \\
Caughey and Palmer (1979): CBL & - & - & 1 to 200 & - \\
Guillemet et al. (1983): CBL & - & - & 5 to 30 & - \\
PYREX measurements & & & - & - \\
Attié (1994): close to the Pyrénées & & & & 133 \\
$\quad$ lower levels) & 1.1 & -25 & 100 & $250-1250$ \\
Above the Pyrénées (upper levels) & 0.5 & -15 & $1-5$ & \\
\hline
\end{tabular}



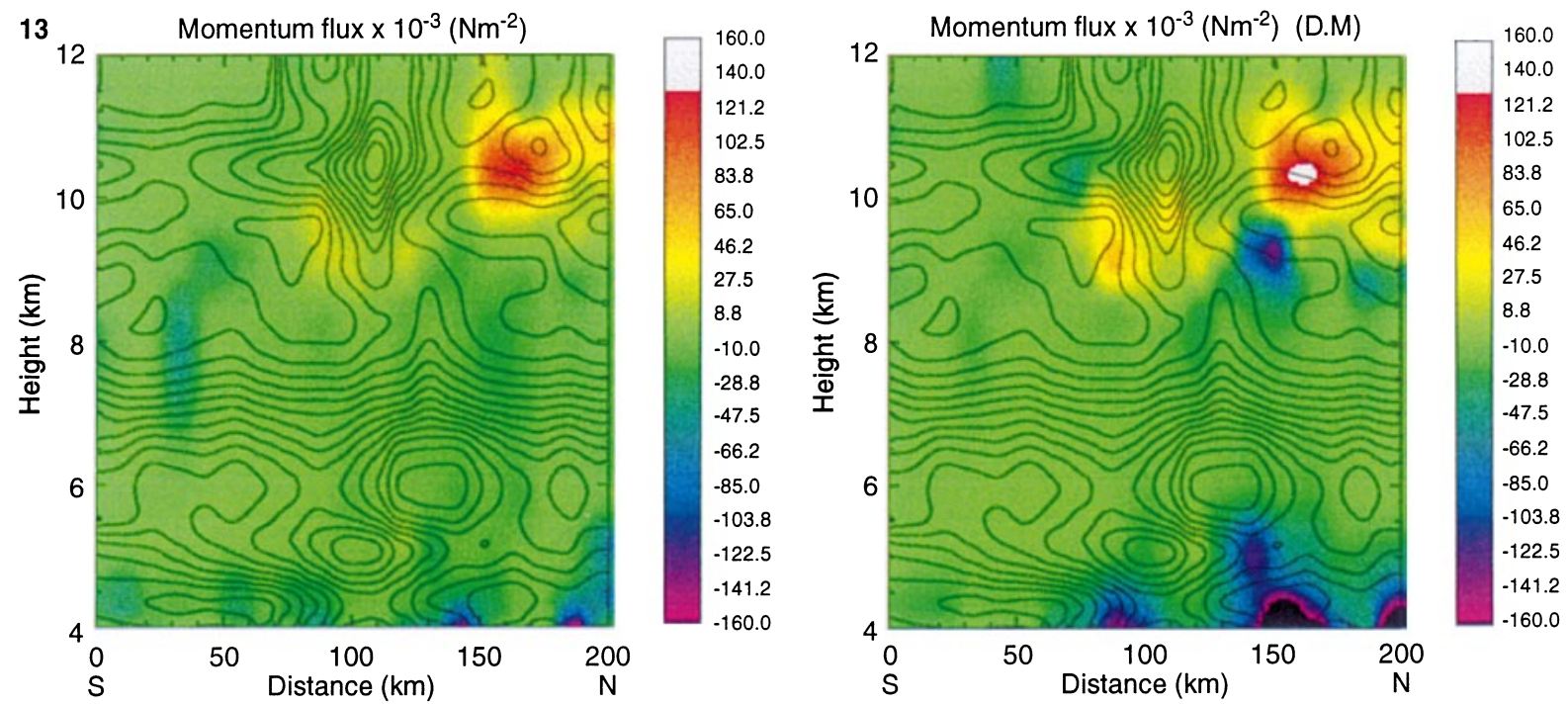

Fig. 13. Colors: turbulent momentum flux (in $\mathrm{N} \mathrm{m}^{-2}$ ) computed by eddy-correlation (left) and inertial-dissipation (right) method. The black isolines reproduce the horizontal wind presented in Fig. 8, e. g. from 15 October

downward transfer (value of $-12 \mathrm{~W} \mathrm{~m}^{-2}$ ) at about $40 \mathrm{~km}$ downstream of the top of the mountain (abscissa $140 \mathrm{~km}$ ). The values of $H$ observed at higher altitudes above the Pyrenees have the same order of magnitude as those typically observed in a stably stratified boundary layer or close to the mountain. However, they are 10 times weaker than those observed in a convective boundary layer within the lower layers (see Table 2). The vertical gradient of flux can to be compared to those of the horizontal advection terms in the budget equation (Eq. 4). Moreover, the vertical gradient of $\overline{w^{\prime} \theta^{\prime}}$ is not important and remains negligible in comparison with the horizontal advection terms. This validates the assumption on the computation of the mean vertical velocity. The fields of TKE and $\epsilon$ (Fig. 15) have a similar shape, which shows that the area of TKE production coincides with the area of TKE dissipation. The maximum of TKE $\left(1.2 \mathrm{~m}^{2} \mathrm{~s}^{-2}\right)$ and $\epsilon\left(5 \times 10^{-4} \mathrm{~m}^{2} \mathrm{~s}^{-3}\right)$ is located in the large oscillation region at high altitude. A second maximum of $\epsilon\left(10^{-4} \mathrm{~m}^{2} \mathrm{~s}^{-3}\right)$ is also reached at a $4 \mathrm{~km}$ altitude in the deceleration zone of the airflow. We also compare the vertical component of TKE $\left(\sigma_{w}\right)$, the dissipation rate of TKE and the inertial length-scale $l_{\epsilon}$ with reference parameters obtained in the boundary layer (Table 2). The values of $\epsilon$ observed above the mountain are weaker than those observed in the boundary layer (between $10^{-3}$ and $10^{-2} \mathrm{~m}^{2} \mathrm{~s}^{-3}$ ). The maximum of $\sigma_{w}$ (about $0.5 \mathrm{~m} \mathrm{~s}^{-1}$ ) is weaker than that encountered close to the mountain $\left(1.1 \mathrm{~m} \mathrm{~s}^{-1}\right)$ but is nearly twice as big as those observed in stably stratified
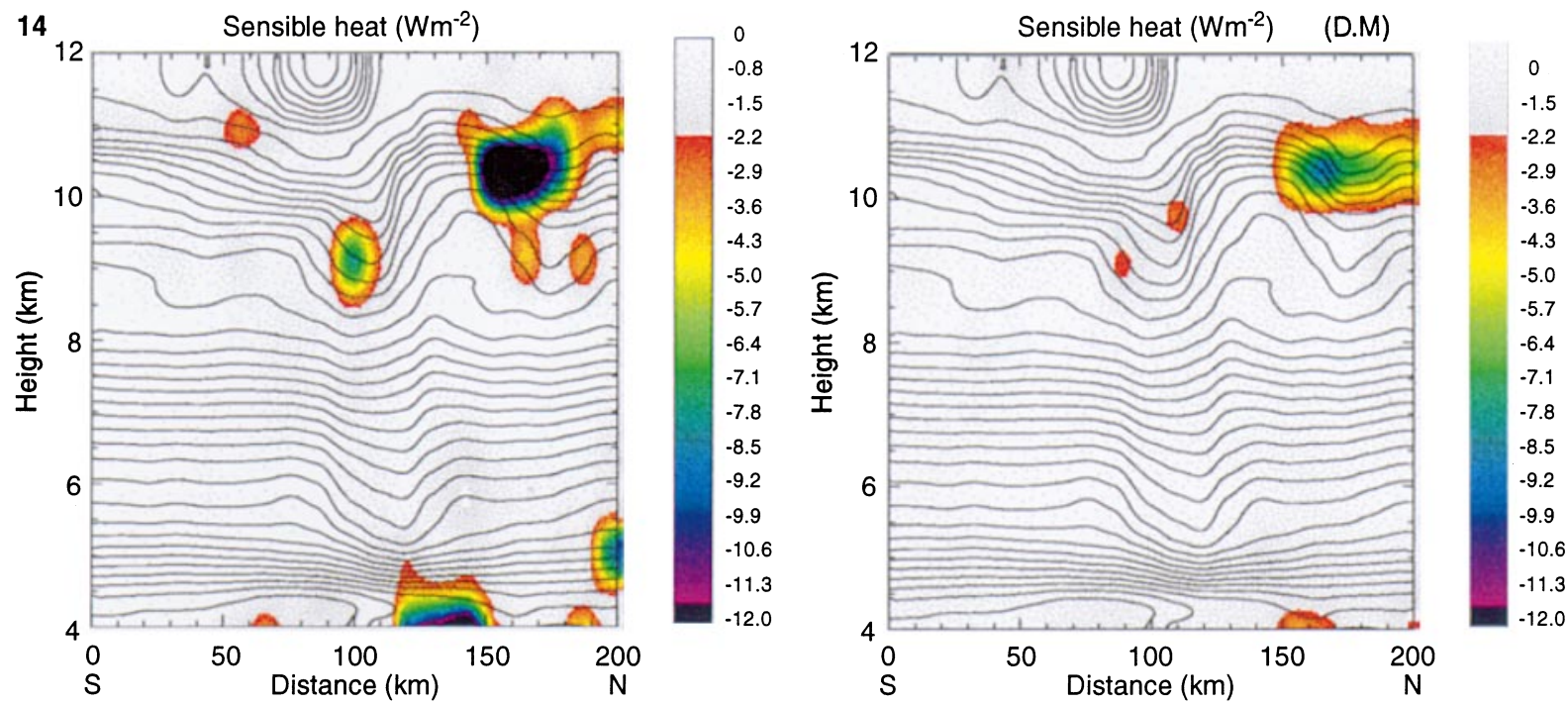

Fig. 14. Colors: turbulent sensible heat flux (in $\mathrm{W} \mathrm{m}^{-2}$ ) computed by eddy-correlation (left) and inertial-dissipation (right) method. The black isolines reproduce the potential temperature presented in Fig. 8, 15 October example 

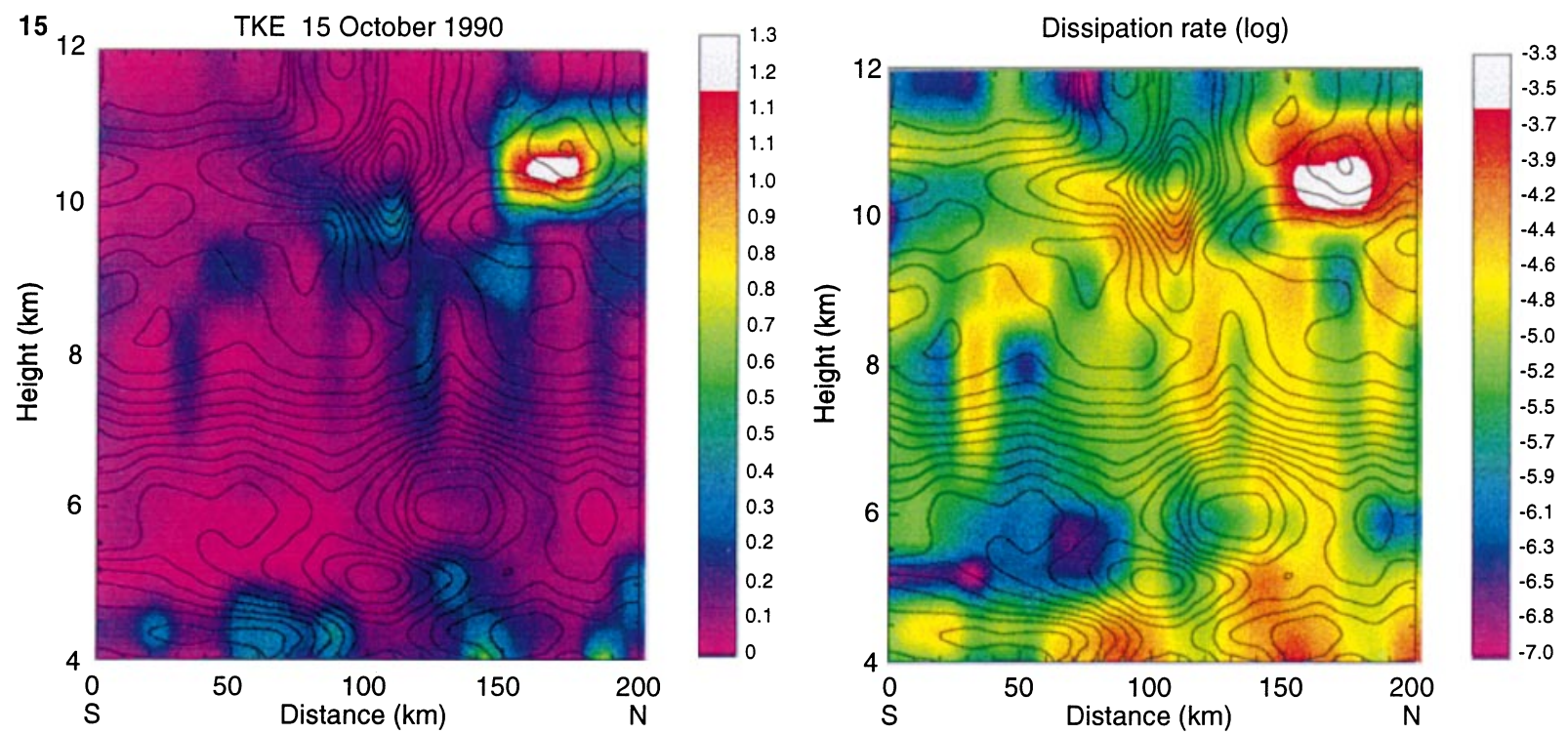

Fig. 15. Colors: TKE (in $\mathrm{m}^{2} \mathrm{~s}^{-2}$ ) (top) and decimal logarithm of TKE dissipation rate (bottom). The black isolines reproduce the horizontal wind presented in Fig. 8, 15 October example

layers, which shows that the dynamical effect is important at high altitude. The combination of $\sigma_{w}$ and $\epsilon$ allows us to calculate the inertial length-scale $l_{\epsilon}$ which allows comparison of the cases together. In the stronger turbulence regions, we observe values between 250 (upper altitudes) and $1250 \mathrm{~m}$ (lower altitudes) comparable to those observed in the convective boundary layer.

\section{The three successive northerly flow cases}

The temporal evolution of the northerly flow above the Pyrenees is described in Figs. 16 and 17 by thermodynamical and dynamical fields (black isolines) superimposed on their corresponding horizontal advection terms (colors). On the figures corresponding to the northerly flow cases, the flow is from the left. The color table used to describe the horizontal advection is the same for the three days. The white (positive values) and black (negative values) areas correspond to values greater or smaller than the extremum of the color table respectively. Table 3 shows extreme values attained by the various advections.

The dynamical structure of the three days is analyzed from the horizontal wind fields, the horizontal advection of wind and the vertical velocity of the air (Fig. 16). The vertical velocity was computed from the steady-state equation for the conservation of temperature. From 14 November to 16 November, the wind strength varies from 22 to $29 \mathrm{~m} \mathrm{~s}^{-1}$ at $6 \mathrm{~km}$ altitude, without a horizontal gradient whereas at upper altitudes the horizontal gradient becomes stronger. We also note that the 15 November case presents upstream wind strengths stronger than that for the others days, in agreement with the wind deduced from upwind radiosonde soundings. From 14 to 16 November, we observe, just above the top of the mountain at the abscissa of $100 \mathrm{~km}$ at an altitude of about $10 \mathrm{~km}$, negative values reaching to $-1 \times 10^{-2} \mathrm{~m} \mathrm{~s}^{-2}$ of horizontal advection of wind related to the deceleration of the airflow. At lower altitudes (about $4 \mathrm{~km}$ ), we also observe, just above the top of the mountain, a small zone of positive values of horizontal advection ranging on 14 to 16 November from $0.5 \times 10^{-2}$ to $0.8 \times 10^{-2} \mathrm{~m} \mathrm{~s}^{-2}$, that translates as the dynamical impact directly from the mountain. The dynamical effect due to the Pyrenees presents a similar behavior via the horizontal advection of wind. As a matter of fact the fields of horizontal advection of wind of the northerly flow cases are similar and have the same shape and same order of values. Moreover, these latter fields have also the same behavior as the southerly flow example.

The downward vertical velocities are located just above the top of the mountain at the absissae of $100 \mathrm{~km}$ lower altitude $(4 \mathrm{~km})$ with values of about $-1 \mathrm{~m} \mathrm{~s}^{-1}$. At upper altitudes, on the lee side of the mountain at the absissae of $150 \mathrm{~km}$ and for altitudes between $10 \mathrm{~km}$ and $12 \mathrm{~km}$, the vertical velocity presents positive values from 0.3 to $0.9 \mathrm{~m} \mathrm{~s}^{-1}$, from 14 to 16 November, respectively. The temporal evolution of vertical velocity fields shows the formation of a well-marked oscillation on the lee side of the mountain at upper altitudes (16 November) which looks like that observed on 15 October.

The thermodynamical structure is presented via the potential temperature, the specific humidity and their corresponding horizontal advection terms (Fig. 17). The vertical wave just above the top of the mountain is well marked on the potential temperature field with a horizontal gradient of potential temperature increasing from 14 to 16 November between 4 and $6 \mathrm{~km}$ of altitude. The rise in temperature, increasing from 14 to 16 November, may be quantified by the horizontal advection term of temperature. The maximum values 

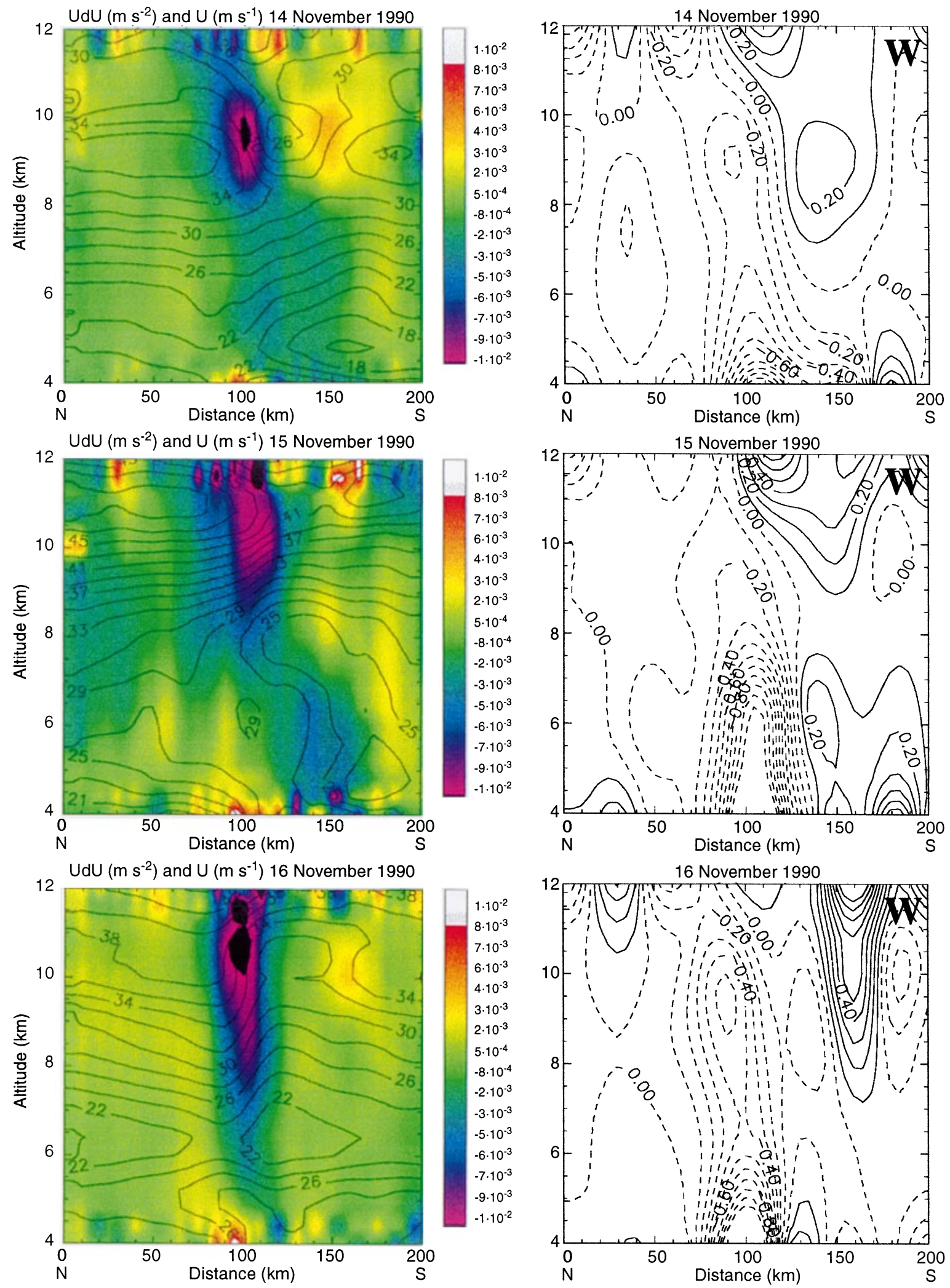

Fig. 16. Left: horizontal advection of wind (colors) (in $\mathrm{m} \mathrm{s}^{-2}$ ) superimposed on wind component field (black isolines); right: vertical velocity (solid lines for upward velocities and dashed lines for downward ones) (in $\mathrm{m} \mathrm{s}^{-1}$ ); from top to bottom: examples of 14, 15 and 16 November 

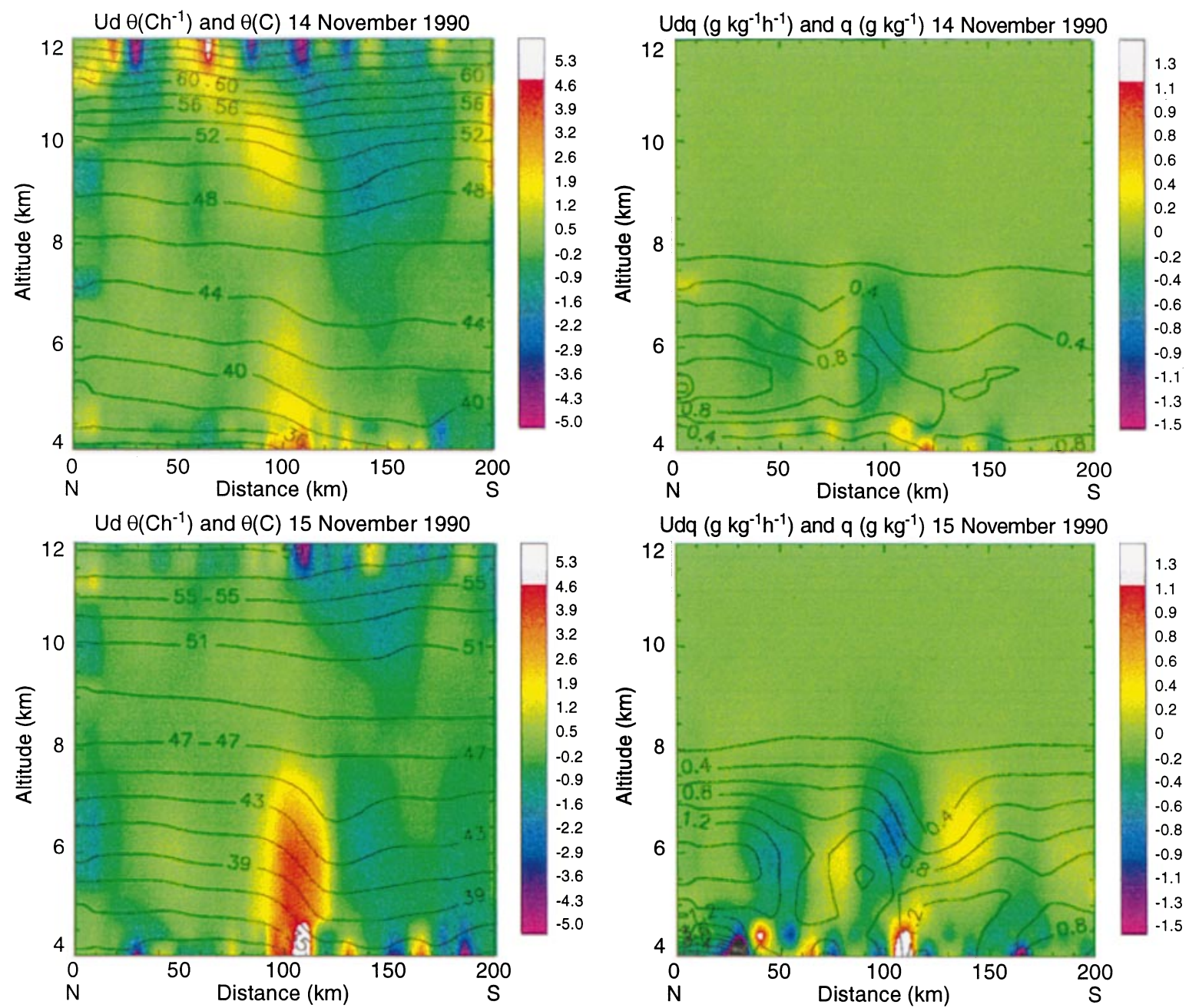

Udq $\left(\mathrm{g} \mathrm{kg}^{-1} \mathrm{~h}^{-1}\right)$ and $\mathrm{q}\left(\mathrm{g} \mathrm{kg}^{-1}\right) 15$ November 1990

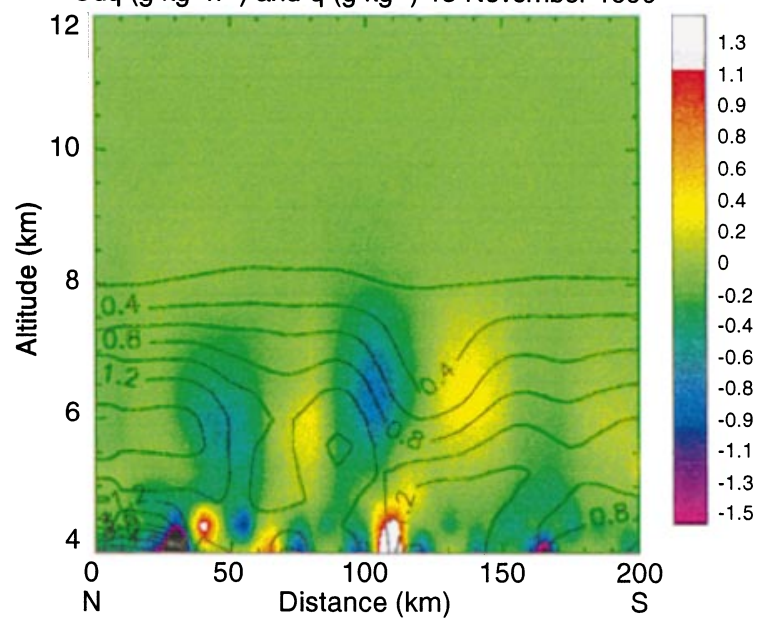

Ud $\theta\left(\mathrm{Ch}^{-1}\right)$ and $\theta(\mathrm{C}) 16$ November 1990

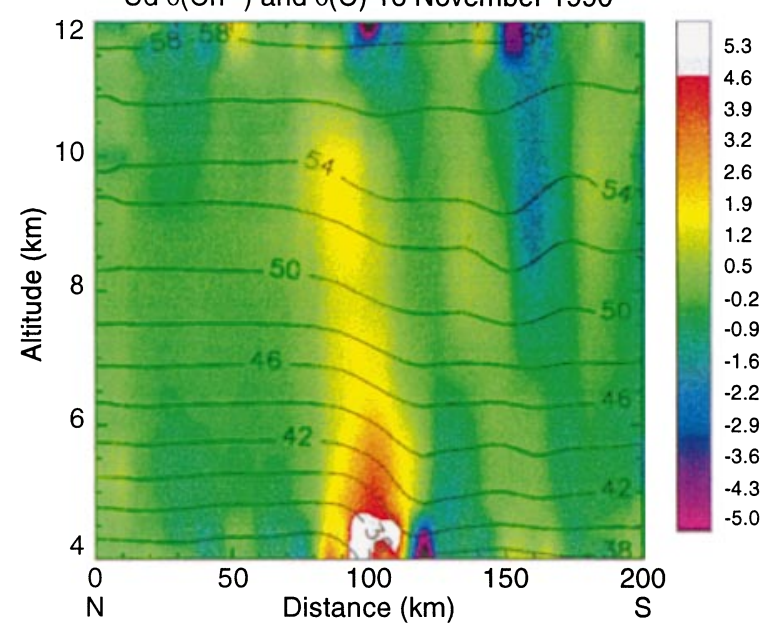

Udq $\left(\mathrm{g} \mathrm{kg}^{-1} \mathrm{~h}^{-1}\right)$ and $\mathrm{q}\left(\mathrm{g} \mathrm{kg}^{-1}\right) 16$ November 1990

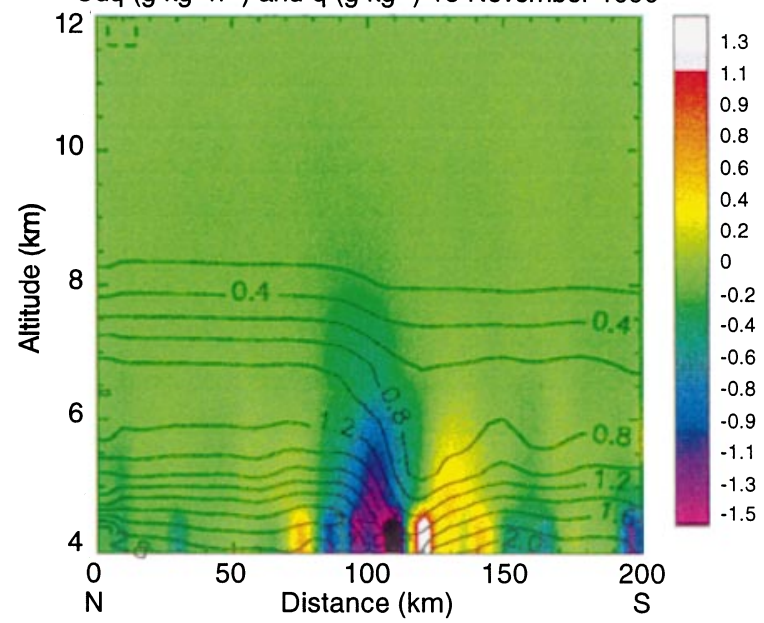

Fig. 17. Left: horizontal advection of potential temperature (colors) (in ${ }^{\circ} \mathrm{C} \mathrm{h}^{-1}$ ) superimposed on isentropes (black isolines) (in ${ }^{\circ} \mathrm{C}$ ); right: horizontal advection of specific humidity (colors) (in $\mathrm{g} \mathrm{kg}^{-1} \mathrm{~h}^{-1}$ ) superimposed on moisture field (black isolines) (in $\mathrm{g} \mathrm{kg}^{-1}$ ); from top to bottom: examples of 14, 15 and 16 November 
Table 3. Extreme values attained by horizontal advection of moisture, potential temperature and horizontal wind in the mountain wave area

\begin{tabular}{llcl}
\hline Case & $\begin{array}{l}\bar{u} \partial \bar{q} / \partial x \\
\mathrm{~g} \mathrm{~kg}^{-1} \mathrm{~h}^{-1}\end{array}$ & $\begin{array}{l}\bar{u} \partial \bar{\theta} / \partial x \\
{ }^{\circ} \mathrm{C} \mathrm{h}^{-1}\end{array}$ & $\begin{array}{l}\bar{u} \partial \bar{u} / \partial x \\
\times 10^{3} \mathrm{~m} \mathrm{~s}^{-2}\end{array}$ \\
\hline 15 October & $-2.5 / 2.0$ & $-11.0 / 14.0$ & $-10.0 / 11.0$ \\
14 November & $-1.5 / 1.5$ & $-4.0 / 7.0$ & $-10.0 / 5.0$ \\
15 November & $-2.5 / 1.0$ & $-4.0 / 18.0$ & $-10.0 / 8.0$ \\
16 November & $-3.5 / 2.0$ & $-6.0 / 20.0$ & $-10.0 / 8.0$ \\
\hline
\end{tabular}

vary from $7{ }^{\circ} \mathrm{C} \mathrm{h}^{-1}$ on 14 November to $20^{\circ} \mathrm{C} \mathrm{h}^{-1}$ on 16 November, mainly at lower altitudes (between 4 and $7 \mathrm{~km}$ at the $100 \mathrm{~km}$ abscissa) showing a heating directly linked to the impact of the airflow on the mountain. Unlike the southerly flow, the northerly flow examples do not present any significant altitude oscillation on the temperature field. On the other hand, the study of the specific humidity and moisture advection demonstrates a drying on the lee side of the mountain, confirming the results of 15 October. The drying effect increases downstream, from 14 November to 16 November, from $-1.5 \mathrm{~g} \mathrm{~kg}^{-1} \mathrm{~h}^{-1}$ to $-3 \mathrm{~g} \mathrm{~kg}^{-1} \mathrm{~h}^{-1}$. The last value is comparable to that obtained on 15 October. As shown in Table 1, the Froude number is weak and presents similar values for the three northerly flow cases. From 14 to 16 November, the increase in the intensity of the mountain wave is probably due to the variation of the leading angle of the upstream airmass: the intensity of the mountain wave (via the thermodynamical fields) is stronger when the upstream airmass is nearly perpendicular to the mountain chain. For the southerly flow case, the Froude number was 0.9 (close to 1) and the upstream airmass was quasi-perpendicular to the Pyrenees chain. This probably explains the stronger intensity of the mountain wave of the southerly flow case which attains upper altitudes. In return, the dynamical effect due to the Pyrenees looks like similar in the four mountain wave cases.

\section{Conclusions}

This work is an experimental study of an orographic airflow above the Pyrenees chain. It analyses a southerly flow case (15 October 1990) and three successive northerly flow cases (14, 15 and 16 November 1990) above the Pyrenees during the PYREX experiment. The data are principally from two research aircraft (a Falcon 20 and a Fokker 27). The flight domain above the Pyrenees chain allowed a careful description of two dimensional fields. These data have been analyzed at two spatial scales: the mesoscale $(\geq 10 \mathrm{~km})$ and the turbulence scale $(\leq 1.5 \mathrm{~km}$; only for 15 October). Three methods of evaluation of the vertical velocity of the air are presented in Appendix B, where the vertical velocity, computed from velocities measurements, is shown to be fairly comparable to that computed from the steadystate equation for the conservation of temperature. The heterogeneous and sporadic turbulence encountered above the mountain was analyzed via turbulent flux by two methods: the eddy-correlation and inertial-dissipation methods. These two methods showed similar results proving a remarkable reliability of aircraft measurements in such experimental conditions. The aircraft measurements have clearly shown the mesoscale and turbulence phenomena induced by the Pyrenees. Numerical models have already been tested on different mountain wave cases and significant hydrostatic and non-hydrostatic simulations have been made by various authors. Tannhauser and Attié (1995) have found good agreement between the amplitudes of the wind components and the corresponding phases measured in trapped lee waves by the aircraft the 15 October and the results of a linear model. Moreover, Satomura and Bougeault (1994) have fairly well simulated the characteristics of lee-waves with a two-dimensional, non-hydrostatic model initiated by upstream radiosonde soundings for the cases of 15 October, 14, 15 and 16 November. For these cases, Elkhalfi et al. (1995) have shown results from a hydrostatic model which agree well with the aircraft observations and have also obtained a good agreement between the simulated and observed profiles of momentum flux.

For the southerly flow case, the analysis clearly shows a downward warm flow, a drying and a global deceleration of the airmass. An important altitude oscillation has been observed on the potential temperature and wind fields, showing strong values of horizontal advection of temperature. We also have shown that this perturbation was linked to an altitude turbulence effect. This effect has been quantified via the turbulent flux (the sensible heat flux $H$ and the momentum flux), the TKE, the dissipation rate and the inertial length-scale. The results have shown a strong mechanical turbulence of intensity comparable to that observed in a convective boundary layer, and a weaker thermal turbulence, comparable to that observed in a stably stratified boundary layer. The analysis of the three successive northerly flows above the Pyrenees has shown the formation of an intense mountain wave on 16 November. The study of the mesoscale terms has shown a thermodynamical effect which was restricted just above the mountain chain. The values of horizontal advection terms were relatively strong in particular for 16 November. However, the dynamical effect, at upper altitudes, looks like that observed during the southerly flow case. The intensity of the mountain wave was probably related to the leading angle and the Froude number of the upstream airflow. For the northerly flow cases, for which the Froude number was almost constant, the study has shown that the mountain wave was stronger if the upstream airmass was nearly perpendicular to the chain. For the southerly flow case above the Pyrenees, the upstream airmass was quasi-perpendicular to the Pyrenees chain and the Froude number was stronger. The mountain wave reached upper altitudes with large values of advection terms, which are one order of magnitude larger than those generally encountered in the boundary layer. 


\section{Appendix A}

\section{Interpolation method}

The data acquired by the Fokker 27 and the Falcon 20 aircraft in the vertical plane perpendicular to the mountain chain are assimilated to build a 2D field. The data were measured along 10 straight and level runs. To build the different fields, the assumed hypothesis is the stationarity of the mesoscale meteorological situation during the period of aircraft measurements. The data are assimilated with an algorithm which permits the definition of the mean parameters in a regular grid (mesh of $400 \mathrm{~m}$ in vertical and $4500 \mathrm{~m}$ in horizontal) describing the flight vertical plane. The mean value of $X$ in a given mesh is obtained by:

$\widetilde{X}=\frac{\sum \overline{X(x, z)} e^{-r^{2}}}{\sum e^{-r^{2}}}$

with

$r^{2}=\frac{d x^{2}}{\sigma_{x}^{2}}+\frac{d z^{2}}{\sigma_{z}^{2}}$

where $\overline{X(x, z)}$ is the measured variable averaged along the aircraft track over a horizontal distance of $10 \mathrm{~km}$ which removes the subgrid-scale phenomena such as trapped lee-waves; $r$ represents the distance between the grid point and the measurement position; the weight parameters $\sigma_{x}$ and $\sigma_{z}$ take into account the non-isotropy between the horizontal and vertical dimensions of the mesh. The chosen value for $\sigma_{x}$ was $5 \mathrm{~km}$ for the whole field, whereas $\sigma_{z}$ varied, according to the vertical distance between the straight and level runs of the aircraft, as follows: for $4 \mathrm{~km} \leq \mathrm{z} \leq 6 \mathrm{~km}, \sigma_{z}=0.3 \mathrm{~km}$; for $6 \mathrm{~km} \leq \mathrm{z} \leq 8 \mathrm{~km}, \sigma_{z}=1.1 \mathrm{~km}$; for $8 \mathrm{~km} \leq \mathrm{z} \leq$ $12 \mathrm{~km}, \sigma_{z}=0.6 \mathrm{~km}$.

\section{Appendix B}

\section{On the computation of the vertical velocity}

We propose three methods of computation of the vertical velocity of the air from aircraft measurements. These methods have already been used by Lilly and Kennedy (1973). The results obtained are compared with the 15 October case.

B.1: vertical velocity deduced from the continuity equation. The method allowing us to compute the vertical velocity of the air has been performed by the following 2D steady state continuity equation.

$\frac{\partial \bar{u}}{\partial x}+\frac{\partial \bar{w}}{\partial z}=0$

To solve this equation, we assume the vertical velocity equals a constant (zero) at the top boundary $(12 \mathrm{~km}$ of altitude). The vertical velocity field obtained (Fig. 18 top) mainly presents two large oscillations above the mountain with maximum values varying from -0.8 to $0.5 \mathrm{~m} \mathrm{~s}^{-1}$. This method gives a fairly good order of magnitude of the vertical velocity at lower levels but cannot show altitude perturbation (seen on vertical velocity fields of 15 October and 16 November for example) because of the top boundary. The method, depending only on $\bar{u}$ component gives a rapid approximative vertical velocity field but has a bad resolution at upper levels.

B.2: direct aircraft vertical velocity. The direct vertical velocity of the air can be calculated by the following relation:

$\bar{w}=V_{p}(i-\Theta)+l \dot{\Theta}+w_{a}$

Where $\Theta$ is the pitch angle of the aircraft, $i$ the attack angle of the airflow, $l$ the distance between the aerodynamic measurement point and the inertial navigation system, $w_{a}$ the aircraft vertical velocity, and $V_{p}$ the true airspeed. The vertical velocity of the air obtained (Fig. 18 middle) perfectly shows an oscillation with maximum values varying from $-1 \mathrm{~m} \mathrm{~s}^{-1}$ to $1.6 \mathrm{~m} \mathrm{~s}^{-1}$ downstream. At an altitude of about $10 \mathrm{~km}$, the field clearly shows a large perturbation of $50 \mathrm{~km}$ horizontal size. A possible source of error on $w_{a}$ lies in the pressure horizontal gradient because the inertial navigation system is stabilized in real time with a static pressure measurement. To give an order of idea, let us consider a pressure horizontal gradient of $1 \mathrm{hPa} / 10 \mathrm{~km}$. Given the groundspeed of the aircraft (about $100 \mathrm{~m} \mathrm{~s}^{-1}$ ), this gives an erroneous vertical velocity of about $0.1 \mathrm{~m} \mathrm{~s}^{-1}$. The stronger the pressure horizontal gradient, the higher the error on the vertical velocity. That is the reason why it is difficult to conclude that the direct vertical velocity of the air is absolutely correct. However, the method permits the comparison of the result with other methods, in particular with the next one.

B.3: vertical velocity deduced from the temperature equation. We use the temperature budget equation which can be expressed as follows:

$\frac{\partial \bar{\theta}}{\partial t}+\bar{u} \frac{\partial \bar{\theta}}{\partial x}+\bar{v} \frac{\partial \bar{\theta}}{\partial y}+\bar{w} \frac{\partial \bar{\theta}}{\partial z}=-\frac{\partial}{\partial z}\left(\overline{w^{\prime} \theta^{\prime}}\right)+S$

where $\bar{u}, \bar{v}$ and $\bar{w}$ are the wind components, $\theta$ the potential temperature and $S$ the sources and sinks (radiative effects, phase transition, etc ...). Moreover, if we assume a two-dimensional and steady airflow and neglect the turbulent terms and the $S$ terms, the equation becomes:

$\bar{w} \frac{\partial \bar{\theta}}{\partial z}=-\bar{u} \frac{\partial \bar{\theta}}{\partial x}$

The vertical velocity field obtained by this method (Fig. 18 bottom) is described in Sect. 6.1. The main drawback of this method is that $\partial \bar{\theta} / \partial z$ is not deduced from a single profile but is calculated from the interpolated field of potential temperature. However, it is fairly similar to that obtained from the previous method and 

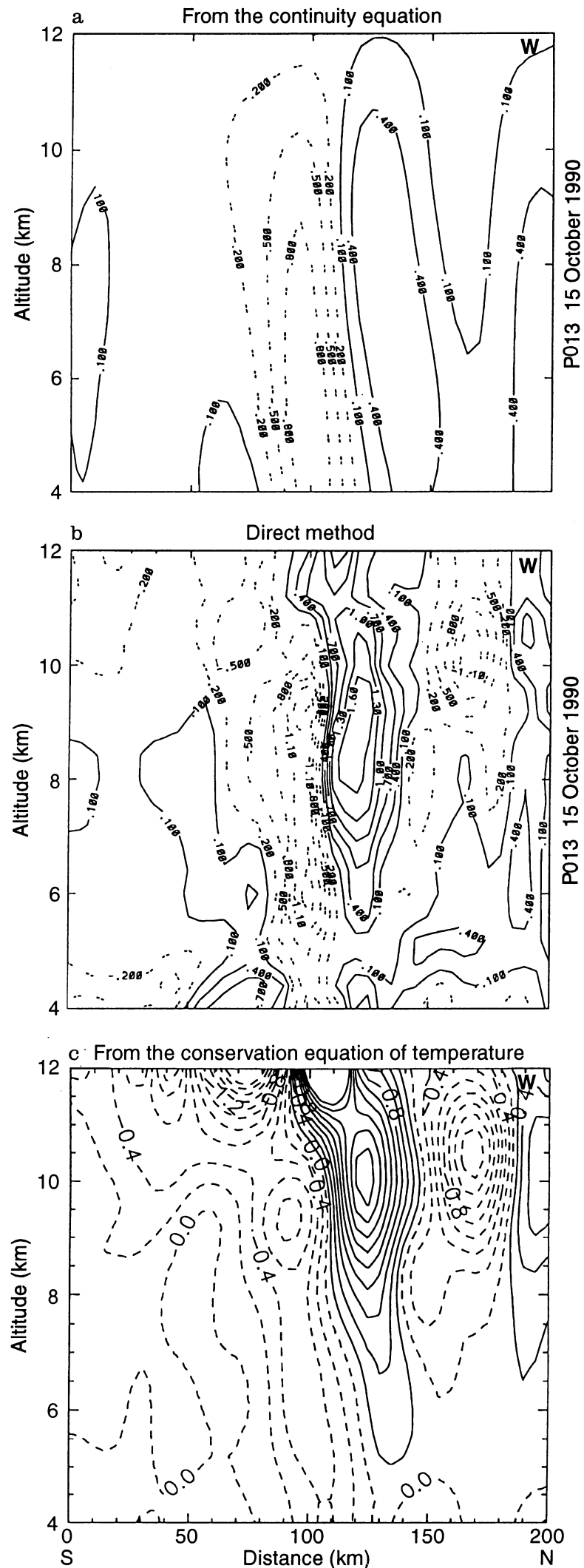

Fig. 18a-c. Vertical velocity of the air (in $\mathrm{m} \mathrm{s}^{-1}$ ) computed with a the continuity equation, b with aircraft airspeed and groundspeed vectors and $\mathbf{c}$ with the steady-state equation for conservation of the temperature. Solid (dashed) lines correspond to upward (downward) velocities, example 15 October the comparison of the three methods permits the guaranteeing of a correct field of vertical velocity of the air with good confidence in values and field structure.

\section{Appendix C}

\section{The inertial-dissipation method}

The principle behind the method consists in calculating the turbulent flux from the dissipation rates of TKE and potential temperature. These dissipation rates are deduced from the measurements of the inertial subrange characteristics of the spectra for velocity and temperature. These characteristics are related to flux through the equations for the evolution of turbulent kinetic energy and temperature variance:

$\frac{\partial \bar{e}}{\partial t}+\overline{u^{\prime} w^{\prime}} \frac{\partial \bar{u}}{\partial z}+\frac{\partial}{\partial z} \overline{w^{\prime} e}+\frac{1}{\rho} \frac{\partial}{\partial z}\left(\overline{p^{\prime} w^{\prime}}\right)-\frac{g}{T} \overline{w^{\prime} \theta^{\prime}}+\epsilon=S_{e}$

$\frac{1}{2} \frac{\partial \overline{\theta^{\prime 2}}}{\partial t}+\overline{w^{\prime} \theta^{\prime}} \frac{\partial \bar{\theta}}{\partial z}+\frac{1}{2} \frac{\partial}{\partial z} \overline{w^{\prime} \theta^{\prime 2}}+N_{\theta}=S_{\theta}$

where $e$ denotes TKE; $u^{\prime}, v^{\prime}$ and $w^{\prime}$ the fluctuations of longitudinal, transversal and vertical wind components; $p^{\prime}$ the pressure fluctuations; $\rho$ the density; $\theta$ the potential temperature; $g / T$ the buoyancy parameter; $\epsilon$ the dissipation rate of TKE; $N_{\theta}$ the half variance destruction rate in temperature; $S_{e}$ and $S_{\theta}$ local sources and sinks for $e$ and $\theta^{\prime 2}$. The principle of the method consists in using a simplified form of these equations, in particular in neglecting the terms for local sources and sinks, vertical turbulent transport of variance and the term related to pressure fluctuation (for a discussion on the validity of these hypotheses see, e.g. Large and Pond 1982; Dyer and Hicks 1970; Fairal and Larsen 1986). Moreover, the method has already been employed in the context of aircraft measurements within the surface boundary layer by Durand et al. (1991). We deduce the following formulation giving the turbulent momentum flux and the turbulent sensible heat flux.

$\overline{u^{\prime} w^{\prime}} \frac{\partial \bar{u}}{\partial z}-\frac{g}{T} \overline{w^{\prime} \theta_{v}^{\prime}}+\epsilon=0$

$\overline{w^{\prime} \theta^{\prime}} \frac{\partial \bar{\theta}}{\partial z}+N_{\theta}=0$

which can be rewritten as:

$\overline{w^{\prime} \theta^{\prime}}=-N_{\theta} / \frac{\partial \bar{\theta}}{\partial z}$

$\overline{u^{\prime} w^{\prime}}=-\left[\epsilon+\frac{g / T N_{\theta}}{\frac{\partial \bar{\theta}}{\partial z}}\right] /(\partial \bar{u} / \partial z)$

Acknowledgements Funding was provided by Météo-France, INM, INSU (ARAT, PAMOS and PAMOY programs), CNES, EDF, DLR, and Région Midi Pyrénées. Much technical help was 
provided by CEV, ENM, and the French and Spanish Airforce and Air Control authorities. We would like to express our deep appreciation to the many colleagues who have participated in the success of the experiment through enormous personal commitment.

Topical Editor L. Eymard thanks K. P. Hoinka for his help in evaluating this paper.

\section{References}

Attié, J. L., Etude d'un écoulement près d'un relief á partir de moyens aéroportés (Expérience PYREX), Ph.D Thesis, 1694, Université Paul Sabatier, France. 1994.

Bénech, B., J. L. Attié, A. Blanchard, P. Bougeault, P. Cazaudarré, A. Druilhet, P. Durand, E. Koffi, P. Prudhomme, and D. S. Tannhauser, Observation of lee waves above the Pyrénées (French Spanish PYREX experiment), Technical Soaring, XVIII, 7-12, 1994.

Bögel, W., and R. Baumann, Test and calibration of the DLR Falcon wind measuring system by maneuvers, J. Atmos. Ocean. Tech., (8), 1, 5-18, 1991.

Bougeault, P., Are 2D simulations a good approximation of orographic flows? An example from PYREX. Proc 6th Conference on Mesoscale Processes, Am. Meteorol. Soc., 467-470, 1994.

Bougeault, P., and C. Mercusot, Atlas des analyses PERIDOT de l'expérience PYREX (in French), CNRM/GMME, Toulouse, 1992.

Bougeault, P., A. Jansa Clar, J. L. Attié, I. Beau, B. Bènech, R. Benoit, P. Bessemoulin, J. L. Caccia, B. Carissimo, J. L. Champeaux, M. Crochet, A. Druilhet, P. Durand, A. Elkhalfi, A. Genoves, M. Georgelin, K. P. Hoinka, V. Klaus, E. Koffi, V. Kotroni, C. Mazaudier, J. Pelon, M. Petitdidier, Y. Pointin, D. Puech, E. Richard, T. Satomura, J. Stein, and D. S. Tannhauser, The atmospheric momentum budget over a major mountain range: first results of the PYREX field program, Ann Geophysicae, 11, 395-418, 1993.

Bougeault, P., A. Jansa Clar, B. Bénech, B. Carissimo, J. Pelon, and E. Richard, Momentum budget over the Pyrénées: the PYREX experiment, Bull. Am. Meteorol. Soc., 71, 806-818, 1990.

Brown, P. R. A, Aircraft measurements of mountain waves and their associated momentum flux over the British Isles, Qt. J. R. Meteorol. Soc., 109, 849-865, 1983.

Caughey, S. J., and S. G. Palmer, Some aspects of turbulence structure through the depth of the convective boundary layer, Qt. J. R. Meteorol. Soc., 105, 811-827, 1979.

Caughey, S. J., J. C. Wyngaard, and J. C. Kaimal, Turbulence in the evolving stable boundary layer, J. Atmos. Sci., 36, 10411052, 1979.

Clark, T. L., A small-scale dynamic model using a terrainfollowing coordinate transformation, J. Computat. Phys., 24, 186-215, 1977.

Clark, T. L., and M. J. Miller, Pressure drag and momentum fluxes due to the Alps. II: representation in large-scale atmospheric models, Qt. J. R. Meteorol. Soc., 117, 527-552, 1991.

Druilhet, A., P. Durand, and F. Saïd, Application des mesures de turbulence aéroportées àl'étude de la physique de l'atmosphère. Analyse de différentes conditions dans la basse troposphère, Proc. Journées d'étude de la turbulence en altitude, Ed. M. Coantic and IMST, 1989.

Durand, P., L. de Sà, A. Druilhet, and F. Saïd, Use of the inertialdissipation method for calculating turbulent fluxes from lowlevel airborne measurements, J. Atmos. Ocean. Tech., 8, 78-84, 1991.
Durran, D. R., Another look at the downslope windstorms. Part I: on the development of analogue to supercritical flow in an infinitely deep, continuously stratified fluid, J. Atmos. Sci., 43, 2527-2543, 1986.

Durran, D. R., and J. B. Klemp, The effects of moisture on trapped mountain lee waves, J. Atmos. Sci., 39, 2490-2506, 1982.

Durran, D. R., and J. B. Klemp, A compressible model for the simulation of moist mountain waves, Mon. Weather Rev., 111, 2341-2361, 1983.

Dyer, A., and B. B. Hicks, Flux-gradient relationships in the constant flux layer, Q. J. R. Meteorol. Soc., 96, 715-721, 1970.

Elkhalfi, A., M. Georgelin, and E. Richard, Two-dimensional simulations of mountain waves observed during the PYREX experiment, Mon. Weather Rev., 123, 2149-2164, 1995.

Fairall, C. W., and S. E. Larsen, Inertial-dissipation methods and turbulent fluxes at the air-ocean interface, Boundary-Layer Meteorol., 34, 287-301, 1986.

Guillemet, B., H. Isaka, and P. Mascart, Molecular dissipation of turbulent fluctuations in the convective mixed layer. Part I: height variations of dissipation rates, Boundary-Layer Meteorol., 27, 141-162, 1983.

Hammam, A., Application des ballons à volume constant à l'étude de la basse atmosphère, Ph.D Thesis. Universitè Paul Sabatier, Toulouse, 1991.

Hoinka, K. P., Observations of a mountain-wave event over the Pyrénées, Tellus, 36 A, 369-383, 1984.

Hoinka, K. P., Observations of the airflow over the Alps during a foehn event, Qt. J. R. Meteorol. Soc., 111, 199-224, 1985.

Hoinka, K. P., and T. L. Clark, Pressure drag and momentum fluxes due to the Alps, I-Comparison between numerical simulations and observations, Qt. J. R. Meteorol. Soc., 117, 495-525, 1991.

Kim, J., and L. Mahrt, Momentum transport by gravity waves, $J$. Atmos. Sci., 49, 736-748, 1992.

Küettner J. P. Scientific results of the Alpine Experiment, in World Meteorological Organization (2 volumes) available from WMO secretariat, Geneva, 1986.

Large, W. G., and S. Pond, Open-ocean momentum flux measurements in moderate to strong winds, J. Phys. Oceanogr., 11, 324-336, 1982.

Lenschow, D. H., Aircraft measurements in the boundary layer, in Probing the atmospheric boundary layer, Ed. D.H. Lenschow, American Meteorological Society, 39-56, 1986.

Lilly, D. K., Wave momentum flux - a GARP problem, Bull. Am. Meteorol. Soc., 53, 17-23, 1972.

Lilly, D. K., and E. J. Zipser, The front range windstorm of January 11, 1972, Weatherwise, 25, 56-63, 1972.

Lilly, D. K., and P. J. Kennedy, Observations of a stationary mountain wave and its associated momentum flux and energy dissipation, J. Atmos. Sci., 30, 1135-1152, 1973.

Lilly, D. K., J. M. Nicholls, R. M. Chervin, P. J. Kennedy, and J. B. Klemp, Aircraft measurements of wave momentum flux over the Colorado Rocky Mountains, Qt. J. R. Meteorol. Soc., 108, 625642, 1982.

Satomura, T., and P. Bougeault, Numerical simulation of lee wave events, J. Meteorol. Soc. Jap., 72(2), 173-195, 1994.

Smith, R. B., The influence of mountains on the atmosphere, in Advances in geophysics, Academic Press, 21, 1979.

Tannhauser, D., and J. L Attié, Linear analysis of the wave field during a lee wave event of the PYREX campaign, Meteorol. Z., 4, 203-208, 1995.

Xue, M. and A. J. Thorpe, A mesoscale numerical model using the nonhydrostatic pressure-based sigma-coordinate equations: model experiments with dry mountain flows, Mon. Weather Rev., 119, 1168-1185, 1991. 